\title{
LA CONFUSA ARMONIZACIÓN DE LOS DELITOS DE MANIPULACIÓN DE MERCADO (ART. 284 CP) POR LA L.O. 1/2019
}

\begin{abstract}
Antonio Doval Pais ${ }^{1}$
Resumen: La Directiva 2014/57/EU de abuso de mercado impuso a todos los Estados Miembros la obligación de incorporar sanciones penales para al menos las conductas graves de abuso y de manipulación de mercados financieros, así como penas de prisión que como mínimo pudieran alcanzar una determinada duración. La reforma del Código Penal español efectuada por la L.O. 1/2019 tuvo como uno de sus objetos transponer dicha norma europea, que afectó en diversos aspectos a los delitos de manipulación de mercado y uso de información privilegiada recogidos en los artículos 284 y 285 . El propósito de este trabajo es analizar el resultado de la reforma en lo que se refiere en particular a los delitos de manipulación de mercado, atendiendo a las novedades relativas a las conductas, a los objetos materiales y a otros requisitos, poniendo el foco en los problemas que la doctrina y la jurisprudencia habían advertido con respecto a estos delitos y aportando criterios para la interpretación de sus complejos elementos típicos y formulaciones.
\end{abstract}

Recibido: julio 2019. Aceptado: febrero 2020

1 Catedrático de Derecho Penal. Orcid ID 0000-0003-3348-2504. Departamento de Derecho Internacional Público y Derecho Penal. Facultad de Derecho. Universidad de Alicante. Apdo. correos 03080 Alicante. E-mail: antonio.doval@ua.es 
Palabras clave: delitos socioeconómicos, Directiva 2014/57/EU, manipulación de mercado, integridad de los mercados financieros, confianza de los inversores.

THE CONFUSING HARMONIZATION OF THE CRIMINAL OFFENCES OF MARKET MANIPULATION (ART. 284 CP) BY THE ORGANIC ACT 1/2019

\begin{abstract}
The Directive 2014/57/EU on market abuse imposed the introduction of criminal sanctions for at least serious market abuse and market manipulation conducts on all Member States. According to this Directive, these should be punished with a maximum term of imprisonment of a minimum number of years. One of the main aims of the Spanish Penal Code reform put into effect by the L.O. 1/2019 was the transposition of this European standard, which affected in various aspects of the crimes of market manipulation and unlawful disclosure of inside information included in articles 284 and 285. The purpose of this paper is to analyze the results of the reform which concern particularly the criminal offences of market manipulation, taking into account the modification related to behaviors, material objects and other elements of the crimes. The paper focuses on the problems that the doctrine and jurisprudence have raised regarding these crimes and provides criteria for the interpretation of their complex legal elements and formulations. Key words: socio-economic crimes, Directive 2014/57/EU, market manipulation, integrity of financial markets, investor confidence.
\end{abstract}

\title{
I. Introducción. Crisis económica y abusos de mercado
}

La gran crisis económica que estalló en 2008 puso al descubierto defectos que afectaban a la transparencia y al funcionamiento de unos mercados financieros muy avanzados tecnológicamente en los que cada vez compiten productos más complejos e intervienen más participantes inexpertos, incapaces de valorar correctamente los riesgos y de tomar sus propias decisiones de inversión, además de empresas de servicios de inversión cuyos 
gobiernos corporativos presentan también graves carencias de controles y contrapesos efectivos ${ }^{2}$.

Los riesgos para los inversores, para el propio mercado y para los Estados, precisamente, se materializaron en la monumental crisis que ocasionó la gran recesión y que produjo inmensos daños al sistema de crédito, al sistema productivo y a los ciudadanos en general, con un gran aumento de las tasas de paro, la precarización del mercado de trabajo y el aumento de la desigualdad. Muchos de los daños se debieron a comportamientos abusivos ${ }^{3}$.

La conexión directa de las causas de la crisis con abusos en los mercados financieros, por un lado, despertó la percepción generalizada de los ciudadanos sobre las posibilidades de manipulación de los mercados y su preocupación sobre las actuaciones de los poderes públicos frente a las conductas de abuso de quienes intervienen en los mismos (inversores, empresas de inversión, entidades de crédito e incluso autoridades supervisoras o reguladoras). Pero, además, por otro lado, ha preocupado mucho a los Estados por las gravísimas repercusiones de la crisis financiera en el propio crecimiento económico y en las condiciones de vida de los ciudadanos.

Desde finales de los años ochenta varios Estados europeos habían empezado a regular el sector financiero ${ }^{4}$, pero las

2 Véase el Preámbulo de la Directiva 2014/65, del Parlamento Europeo y del Consejo, relativa a los mercados de instrumentos financieros (MiFID II), considerandos (4) y (5).

3 Es un hecho admitido. Véase, por todos, Joseph E. Stiglitz (premio Nobel de Economía en 2001 y profesor en la Universidad de Columbia, Nueva York) diciendo: "The new low in the financial crisis is the fruit of a pattern of dishonesty on the part of financial institutions, and incompetence on the part of policymakers [...] Some of America's best and brightest were devoting their talents to getting around standards and regulations designed to ensure the efficiency of the economy and the safety of the banking system" "The fruit of hypocrisy", en The Guardian, 16 de septiembre de 2008). También, Estefanía, J.: "Crisis financiera, abusos y corrupción”, en El Notario del Siglo XXI, núm. 31, mayo-junio 2010.

4 Las primeras iniciativas de los países europeos tuvieron por objeto la regulación del uso de información privilegiada y alguna de ellas se remonta más 
iniciativas más importantes para garantizar la certeza y la igualdad de los participantes en el mercado se debieron a la Unión Europea ${ }^{5}$. Para las instituciones europeas legiferantes, "un mercado financiero integrado y eficiente y una mayor confianza de los inversores requieren integridad del mercado. El buen funcionamiento de los mercados de valores y la confianza del público en los mercados son requisitos imprescindibles para el crecimiento y la riqueza económicos. El abuso de mercado daña la integridad de los mercados financieros y la confianza del público en los valores, los instrumentos financieros derivados y los índices de referencia." ${ }^{\prime 6}$

En efecto, es máxima la convicción de la Unión Europea sobre la importancia fundamental del mercado y la necesidad de su regulación. Por ello, ha impulsado diversas normas dirigidas a evitar los abusos en el mercado. Las primeras establecieron una serie de disposiciones y medidas de carácter administrati$v^{7}$, pero hace unos años se realizó un nuevo esfuerzo con el fin de reforzar el correcto funcionamiento de los mercados. Se trata

atrás. Véase sobre ello Faraldo Cabana, P.: "Algunos aspectos del delito de uso de información reservada en el mercado de valores en el proyecto de Código Penal de 1994", en Estudios penales y criminológicos, núm. 18, 1994-1995, pp. 49-50.

5 La UE ha venido ocupándose de ello también desde entonces. Sus primeras actuaciones normativas para prevenir las conductas abusivas se remontan a la Directiva 89/592/CEE del Consejo, de 13 de noviembre de 1989, sobre coordinación de las normativas relativas a las operaciones con información privilegiada.

6 Directiva 2014/57/UE del Parlamento Europeo y del Consejo de 16 de abril de 2014, sobre las sanciones penales aplicables al abuso de mercado (Directiva sobre abuso de mercado), considerando (1). Casi idéntico, el considerando (2) de la Directiva 2003/6/CE del Parlamento Europeo y del Consejo de 28 de enero de 2003 sobre las operaciones con información privilegiada y la manipulación del mercado (abuso del mercado).

7 Como las ya citadas Directiva 89/592/CEE y Directiva 2003/6/CE, ordenando adoptar las medidas administrativas apropiadas, o la imposición de sanciones administrativas, contra las personas responsables cuando no se hayan cumplido las disposiciones adoptadas con arreglo a las mismas. 
de la Directiva 2014/57, sobre abuso de mercado $^{8}$, mediante la cual la Unión Europea, haciendo uso de sus competencias de armonización del Derecho penal nacional, optó también en esta materia por una intervención de contenido penal ${ }^{9}$.

\section{La Directiva 2014/57 sobre abuso de mercado y la refor- ma de la disciplina penal del abuso de mercado}

La Directiva 2014/57 se dirige a evitar abusos del mercado en forma de realización de operaciones con información privilegiada, comunicación ilícita de esta información y manipulación de mercado, y alcanza a cuantas personas o entidades realicen actividades relacionadas con los mercados de valores y otros instrumentos financieros. La norma europea parte de que es esencial reforzar el cumplimiento de las disposiciones sobre abuso de mercado "previendo sanciones penales que demuestren una desaprobación social de carácter más severo frente a la que denotan las sanciones administrativas", así como transmitir "a la población y a los posibles infractores la enorme seriedad con que las afrontan las autoridades competentes"10. Con este objeti-

8 Directiva 2014/57, del Parlamento y del Consejo, sobre las sanciones penales aplicables al abuso de mercado (véase la nota 6).

9 Esta intervención directamente punitiva vino a sumarse a otras similares consideradas imprescindibles para garantizar la ejecución eficaz de la política de la Unión (art. 83.2 del Tratado de Funcionamiento de la Unión Europea), como las de las normas siguientes: Directiva 2008/99/CE, relativa a la protección del medio ambiente mediante el Derecho penal; Decisión Marco 2008/913/JAI, relativa a la lucha contra determinadas formas y manifestaciones de racismo y xenofobia mediante el Derecho penal; Directiva 2014/62/UE, relativa a la protección penal del euro y otras monedas frente a la falsificación; Directiva (UE) 2017/1371 sobre la lucha contra el fraude que afecta a los intereses financieros de la Unión a través del Derecho penal; o Directiva (UE) 2018/1673, relativa a la lucha contra el blanqueo de capitales mediante el Derecho penal. Sobre los ámbitos de armonización específicamente penal, véase De la Mata Barranco, N.: Derecho penal europeo y legislación española: Las reformas del Código Penal, Ed. Tirant lo Blanch, Valencia, 2015, pp. 33-40.

10 Considerando (6). No obstante, acerca de la necesidad de una intervención específicamente punitiva, véase, críticamente, Estrada i Cuadras, A.: "Pre- 
vo, su propósito es que se asegure la sanción penal en los casos "graves" de abuso de mercado, cometidos intencionalmente. Y, para ello, describe una serie de comportamientos que deberán incluirse en la legislación penal de los Estados miembros, en la medida en que puedan tenerse por graves considerando sus efectos en la integridad del mercado, en la estabilidad del objeto (valor, instrumento financiero, etc.), el volumen del beneficio o de las pérdidas evitadas, o de la propia operación, o el carácter profesional del agente, entre otros ${ }^{11}$.

Aunque esta Directiva se aprobó en 2014 y su plazo de transposición expiraba el 3 de julio de 2016, la nueva regulación que establece no ha sido incorporada a nuestro ordenamiento jurídico hasta la reforma del Código Penal efectuada por la L.O. $1 / 2019$, de 20 de febrero, por la que se modifica la Ley Orgánica 10/1995, del Código Penal. De modo que en 2015 se dejó pasar la ocasión de la reforma del Código Penal (con riesgo de incoación por la Comisión de un procedimiento de infracción contra España que podría concluir en la imposición de una multa ${ }^{12}$ ).

La Directiva obliga a reformar el núcleo fundamental del Derecho penal español de la competencia, constituido por los artículos 284 (delitos de alteración de precios) y 285 (delito de uso de información privilegiada, insider trading $)^{13}$. Las modifi-

sente y futuro del delito de alteración de precios (art. 284 Cp)", en InDret, 1/2014, pp. 41-43. También a propósito, sobre los presupuestos acerca de la eficacia disuasoria del Derecho penal, Ortiz de Urbina Gimeno, I.: "Selección de bienes jurídico-penales conforme a la Constitución: El caso de la protección de la competencia”, en Silva Sánchez, J.-Ma./Queralt Jiménez, J.J./Corcoy Bidasolo, M./Castiñeira Palou, Ma.T. (Edits.): Estudios de Derecho penal. Homenaje al profesor Santiago Mir Puig, Ed. B de F, Buenos Aires (Argentina), 2017, pp. 1123-1127.

11 Véanse los considerandos (11) y (12), con respecto a las operaciones con información privilegiada y a la manipulación de mercado, respectivamente.

12 Como expresamente se reconoce en el Preámbulo de la L.O. 1/2019: "la Comisión Europea inició el procedimiento formal de infracción 2016/627, cuyo estado avanzado exige la adaptación inmediata a dicha directiva de nuestro ordenamiento".

13 El primero había sido adaptado en 2010 (L.O. 5/2010, por la que se modifica la Ley Orgánica 10/1995, del Código Penal) a la Directiva 2003/6, sobre las 
caciones han afectado tanto a las conductas (pues no se contemplaban algunas y otras se formulaban de un modo diferente ${ }^{14}$ ), como a la pena de prisión de los delitos del artículo 284, cuyo máximo no alcanzaba los ahora preceptivos cuatro años, sino que se limitaba a dos.

La transposición ha tenido lugar mediante la incorporación de las exigencias de la Directiva al Código Penal y la revisión de la compatibilidad con la misma del texto penal precedente. Aunque había otras posibilidades ${ }^{15}$. La norma europea establece unos "contenidos penales" mínimos que han de cumplir las legislaciones de todos los Estados miembros. De modo que el régimen penal adoptado por los Derechos nacionales podría ser más amplio. El resultado de la reforma de 2019 en España,

operaciones con información privilegiada y la manipulación del mercado, aunque no obligaba a los Estados miembros a exigir responsabilidad específicamente penal por las conductas de uso de información privilegiada y de difusión de noticias o rumores con información falsa, siempre con respecto a "valores o instrumentos financieros". Además, el castigo previsto para la difusión de noticias o rumores con información falsa se condicionó a la obtención de un beneficio o a la causación de un perjuicio económico superior a $300.000 €$. Y la reforma también modificó el régimen de perseguibilidad de los delitos de los artículos 284 y 285 , sustrayéndolos a la necesidad de denuncia de la persona agraviada o de sus representantes legales (art. 287), e incorporó la responsabilidad de las personas jurídicas, al igual que para todos los demás delitos del capítulo (art. 288).

14 Según el Preámbulo de la L.O. 1/2019, antes de la reforma las conductas típicas "no abarcaban todos los supuestos específicamente referidos en la norma europea, que ahora deben sancionarse de forma expresa para cumplir con las exigencias del principio de legalidad penal". La referencia al principio de legalidad es aquí demasiado obvia y parece, más bien, insinuar que tipificar nuevos supuestos es cumplir con el principio de legalidad. Pero, si bajo la regulación anterior estos delitos "no abarcaban todos los supuestos específicamente referidos en la norma europea" era porque no podían ser alcanzados por la interpretación, sin resentirse el principio de legalidad. Y, si ahora se incorporan "los supuestos específicamente referidos en la norma europea", ello solo responde a la lógica exigencia de lex pravvia, que rige para cualquier conducta que se desee incriminar.

15 Con respecto a Alemania, véase Gómez-Jara Díez, C.: El delito de manipulación de mercado (arts. 284.2 y 284.3 CP), Ed. Tirant lo Blanch, Valencia, 2017, p. 15. 
de hecho, conserva alguna conducta que aparece prevista entre las que contempla el Reglamento 596/2014, sobre abuso de mercado ${ }^{16}$. Este instrumento define las infracciones que quedan reservadas al ámbito del Derecho administrativo de los Estados miembros, pero tolera que estos continúen previendo sanciones penales por las mismas infracciones si ya figuraban sujetas al Derecho penal interno a fecha de 3 de julio de 2016 (como en el caso de España) $)^{17}$.

Aunque estas páginas tienen por objeto el análisis de la reforma en lo que se refiere, en particular, a los delitos de manipulación de mercado (art. 284), antes de analizar los aspectos en los que se ha plasmado la modificación, conviene realizar una aproximación a estas figuras para tener presentes algunas de sus características referidas a su injusto y a la praxis aplicativa de los jueces y tribunales al respecto.

\section{Los delitos de manipulación de mercado (art. 284)}

\section{Consideraciones sobre el fundamento del injusto}

Las figuras típicas que caracterizaban originalmente a los actuales delitos del artículo 284 fueron calificadas bajo el Código Penal anterior como "maquinaciones para alterar el precio de las cosas"18, y así se conocen aún a menudo en pronunciamientos de la jurisprudencia. Aunque también han recibido el nombre de "delitos de alteración de precios" (pues la conducta típica tradicional consistía en intentar alterar los precios), la expresión "delitos de manipulación de mercado" se ajusta más al diverso contenido actual de las figuras típicas que comprende.

16 Reglamento (UE) 596/2014 del Parlamento Europeo y del Consejo de 16 de abril de 2014 sobre el abuso de mercado (Reglamento sobre abuso de mercado) y por el que se derogan la Directiva 2003/6/CE del Parlamento Europeo y del Consejo, y las Directivas 2003/124/CE, 2003/125/CE y 2004/72/ CE de la Comisión.

17 Considerando (72).

18 Véase la rúbrica que conservó el Capítulo V del Título XIII (De los delitos contra la propiedad), Libro II, del Código Penal de 1973. 
No obstante, a pesar de los cambios que estos delitos han experimentado en los últimos años, desde su primera redacción en el Código Penal de 1848 se puede observar una línea maestra que siempre les ha caracterizado: la orientación de sus conductas típicas a interferir en la formación de los precios de los productos en el mercado de la libre competencia. Ello tiene relación, desde luego, con intereses de naturaleza patrimonial ${ }^{19}$, pero el núcleo de su injusto no está constituido por ninguna afección de esta clase $^{20}$, sino, como entiende la generalidad de la doctrina y de la jurisprudencia, por su incidencia en el correcto funcionamiento del mercado; en particular, en la "libre competencia" y su papel en la formación de los precios según las leyes del mercado $^{21}$. El Preámbulo de la L.O. 1/2019 ha especificado,

19 Véase, poniéndolo de relieve, Ortiz de Urbina: "Selección de bienes jurídico-penales conforme a la Constitución: El caso de la protección de la competencia”, cit., p. 1122.

$20 C f r$., sin embargo, Quintero Olivares sosteniendo (en un contexto legal muy distinto) "el carácter patrimonial y particularista de estas infracciones, en contraposición con las normas contenidas en leyes especiales [...] en las que es dable ver una neta preponderancia de lo público y comunitario en el interés protegido" (en "Maquinaciones para alterar el precio de las cosas", en Nueva Enciclopedia Jurídica, T. XV, Ed. Seix, 1974, p. 844).

21 García-Pablos de Molina, A.: "Sobre la figura del delito para alterar los precios (naturales) de las cosas", en Cuadernos de Política Criminal, núm. 14, 1981, p. 226 (libertad de competencia, en el marco que permite la Administración); Boix Reig, J.: "Las prácticas restrictivas de la competencia en el Proyecto de Código Penal de 1980", en Cuadernos de Política Criminal, núm. 16, 1982, p. 36 (libertad de competencia); Bajo Fernández, M.: Manual de Derecho penal (Parte Especial). Delitos patrimoniales y económi$\cos$, Ed. Ceura, Madrid, 1987, p. 255 (libre formación de precios); Brage Cendán, S.B.: Los delitos de alteración de precios. Especial referencia a los artículos 262, 281 y 284 CP, Ed. Comares, Granada, 2001, p. 50 (libre concurrencia, aunque señala también el -en mi opinión, discutible- "intervencionismo estatal", como mecanismos de fijación de precios en la economía española); Gómez Pavón, P.: “Algunas cuestiones en torno al art. 284 del Código Penal”, en López Barja de Quiroga, J./Zugaldía Espinar, J.M. (Coords.): Dogmática y Ley penal. Libro homenaje a Enrique Bacigalupo, T. II, Ed. Marcial Pons, Madrid, 2004, p. 956 (mecanismo de fijación de los precios libres conforme a las leyes de mercado); Ortiz de Urbina: "Selección de bienes jurídico-penales conforme a la Constitución: El caso de la protección de la competencia”, cit., p. 1123 (libre competencia); Martínez- 
en esta misma dirección, que "el bien jurídico protegido no se configura tanto en atención al contenido patrimonial o al propio orden socioeconómico, como a la integridad de los mercados y la confianza de los inversores que actúan en ellos". Esto se ha valorado ya como un avance en la medida en que aleja el delito de la perspectiva patrimonialista que se advierte en algunas resoluciones judiciales ${ }^{22}$.

La finalidad político-criminal de la intervención jurídica en esta materia es, sin duda, la protección del interés público que se concentra en torno al mercado (y, particularmente, a los mercados financieros), como fuente de asignación eficiente de recursos para fines productivos. Pero la propia existencia del mercado y su conservación en condiciones de eficiencia dependen de una serie de requisitos como la confianza de los inversores, la transparencia, la libre formación de los precios o, incluso, los propios intereses de los emisores. Estas condiciones instrumentales pueden verse afectadas directamente por comportamientos de abuso de mercado. De modo, pues, que la integridad de mercado constituye un fin de protección que depende directamente de una serie de condiciones a las que se dirige la protección jurídica y,

Buján Pérez, C.: Derecho penal económico y de la empresa. Parte especial, $5^{\text {a }}$ ed. Ed. Tirant lo Blanch, Valencia, 2015, p. 339 (libre concurrencia y el intervencionismo estatal, en cuanto son los elementos que constituyen los mecanismos para fijar los precios en la economía española); Quintero Olivares, G.: "Art. 284", en Quintero Olivares, G. (Dir.)/Morales Prats, F. (Coord..): Comentarios a la Parte Especial del Derecho penal, $3^{\mathrm{a}}$ ed., Ed. Aranzadi, Cizur Menor, 2002, p. 878 (corrección del sistema de formación de los precios); Feijoo Sánchez, B.: "Los delitos de manipulación del precio de cotización de un instrumento financiero del art. 284 CP tras la LO 1/2019. Retos dogmáticos frente a un desatino legislativo", en La Ley Penal. Revista de Derecho penal, procesal y penitenciario, núm. 138, 2019, p. 4 (correcta formación de los precios de cotización como elemento básico para la integridad del mercado). Con respecto a la jurisprudencia, de forma similar a la doctrina mayoritaria, las SSTS 549/1997, de 26-4; 867/2002, 29-7 ("caso Banesto"); 575/2004, de 11-5; y 670/2015, de 30-10.

22 Así, Gómez-Jara Díez, C./Tejada Plana, D.: "La reforma del delito de manipulación de mercado en el Código Penal español: luces, sombras y algún claroscuro", en La Ley, núm. 3974, 2019, p. 3. 
también, la jurídico-penal. Esta relación transitiva entre el fin y los instrumentos en juego, permite no abandonar, en particular en el ámbito del Derecho penal, la referencia al bien jurídico protegido a una genérica "integridad de los mercados" y a la "confianza de los inversores" (como hace la L.O. 1/2019 en su preámbulo).

En definitiva, pues, se concibe como un bien jurídico colectivo. Sin embargo, no puede ocultarse que unas formulaciones tan genéricas difícilmente permitirán anclar con firmeza el injusto de estos delitos. Ello repercutirá directamente en la percepción del daño que supone y, en consecuencia, también, en su perseguibilidad y su castigo. Por ello, se impone la necesidad de determinar de una forma más precisa el bien jurídico.

Ciñéndonos a la manipulación de mercado, el hecho de que se interfiera en la formación de los precios supone introducir variables en su proceso determinación que alteran las reglas de eficiencia en la asignación de recursos (como las razones productivas, en un sentido amplio, que caracterizan al instrumento financiero o al emisor) y puede comportar efectos en la confianza de los inversores y hasta de los propios emisores ${ }^{23}$. Por lo tanto, en línea con la idea de la doctrina y la jurisprudencia al respecto, y sin perjuicio de una ulterior reflexión, es posible concretar

23 Sobre las razones que justifican la prohibición de las conductas de abuso de mercado, véase, con consideraciones similares a las expuestas, Martínez Flórez, A.: "Los fundamentos de la prohibición del abuso de mercado", publicado en Blog de la Facultad de Derecho Universidad Autónoma de Madrid (http://www.blog.fder.uam.es/2019/04/03/los-fundamentos-de-laprohibicion-del-abuso-de-mercado/; consultado el 6-6-2019; con base en el libro de la autora Los fundamentos de la prohibición del abuso de mercado, Ed. Tirant Lo Blanch, Valencia, 2019). Esta autora entiende que, en particular, la manipulación "impide la eficiente asignación de los recursos; repercute en la capacidad de los mercados de valores para asignar los recursos a las inversiones más productivas, perjudicando a los inversores y al conjunto de la economía" (p. 10). Con respecto a la legitimidad de la intervención penal en esta materia, partiendo de las funciones privadas y públicas de los mercados y de los riesgos sistémicos inherentes a los mismos, véase, con más referencias, Gómez-Jara Díez: El delito de manipulación de mercado, cit., pp. 49-51. 
algo más el bien jurídico protegido en la formación de precios conforme a las reglas genuinas de un mercado eficiente ${ }^{24}$.

\section{Precedentes jurisprudenciales}

Es importante conocer cuál ha sido la trayectoria de estos delitos ante los tribunales para poder detectar eventuales problemas puestos de relieve en el momento de su aplicación y para valorar las posibles repercusiones de los cambios legislativos en la materia. Sin embargo, los jueces se han enfrentado muy pocas veces a estos delitos y la escasísima jurisprudencia que se halla permite extraer pocas conclusiones. Ya bajo la regulación anterior se había advertido su tradicional inaplicación ${ }^{25}$; y tampoco después del Código Penal de 1995, ni de sus reformas posteriores, se apreciaron significativas diferencias. No hay una única explicación para esta situación.

24 Como señaló Quintero Olivares, la expresión legal "precios que podrían resultar de la libre concurrencia" (CP 1973), equivalente a la actual, debía entenderse como la alusión a "una situación de normalidad en el mercado" (en "Maquinaciones para alterar el precio de las cosas", cit., p. 847). En la misma línea, Boix Reig se refirió a los "obstáculos artificiales a la libertad de competencia" (en "Las prácticas restrictivas de la competencia en el Proyecto de Código Penal de 1980", cit., p. 36). El planteamiento del texto sobre el injusto de estos delitos se encuentra también en la misma línea del sostenido por Paredes Castañón en "Problemas de tipicidad en las conductas de manipulación de precios de los mercados de valores", en Demetrio Crespo, E. (Dir.): Crisis financiera y Derecho penal económico, Ed. Edisofer, Buenos Aires, 2014, p. 16: "alteración significativa (daño) que la conducta manipuladora produciría sobre los patrones de interacción de todos los agentes económicos participantes en el mercado".

25 Véase Fernández Albor, A.: El agio arrendaticio, Ed. Tecnos, Madrid, 1969, pp. 44 y 45. Aunque la afirmación del texto se debe matizar, pues, como Quintero Olivares advirtió, la "penuria de fallos jurisprudenciales" que aplicasen los correspondientes artículos del Código Penal se debía a la "preponderancia absoluta de la legislación especial [...] en tanto que son numerosas las sentencias del Tribunal Supremo que aplican las leyes especiales sobre delitos de acaparamiento, agio, etc." (en "Maquinaciones para alterar el precio de las cosas", cit., pp. 847 y 843, respectivamente). De hecho, Fernández Albor había constatado la vida que cobraron los arts. 540 y 541 del Código Penal solo por la remisión de la legislación especial a ellos (y, en efecto, este autor proporcionó una lista de casi ciento cincuenta sentencias relativas a su objeto de estudio entre los años 1887 y 1968 en op. cit., pp. 197-198). 
Por un lado, son evidentes las dificultades para el descubrimiento de estos hechos dada la cantidad de variables que determinan la formación de los precios en el mercado. Tampoco se puede ignorar que algunas de las modalidades que el Código Penal castiga no son fáciles de distinguir de comportamientos frecuentemente practicados y descontados por los participantes en el mercado. Además, debe tenerse en cuenta que tampoco los mecanismos de inspección y prevención en la vía administrativa funcionan debidamente e impiden servir de filtro a casos que, por esta razón, resultan arrojados a una persecución penal que difícilmente puede $\operatorname{prosperar}^{26}$. Y la praxis judicial ha sido rígida y formalista, en particular con los requisitos subjetivos de estos delitos ${ }^{27}$. A este panorama tampoco han contribuido tipos penales poco claros y lastrados con las exigencias de unas cuantías escasamente realistas en la práctica, tanto por su difícil determinación como por la posibilidad de que eventualmente los mecanismos de control del mercado se activaran a tiempo ante señales de alarma $^{28}$.

En el pequeño cuerpo de sentencias condenatorias en aplicación del artículo 284 o de su precedente (art. 540 CP 1973), las más importantes son las siguientes: una, que sancionó por utilización de información privilegiada para alterar los precios

26 Véase, con ocasión del Proyecto de Código Penal de 1980, ya, Boix Reig: "Las prácticas restrictivas de la competencia en el Proyecto de Código Penal de 1980", cit., p. 44.

27 Muy crítico, Paredes Castañón (en "Problemas de tipicidad en las conductas de manipulación de precios de los mercados de valores", cit., pp. 20-21 y 252 y ss.).

28 Véase el art. 80 LMV (Suspensión de la negociación de instrumentos financieros), derogado por el Real Decreto-ley 21/2017, de 29 de diciembre, de medidas urgentes para la adaptación del derecho español a la normativa de la Unión Europea en materia del mercado de valores. Tras la reforma de 2018 de la LMV (Real Decreto-ley 19/2018, de 23 de noviembre, de servicios de pago y otras medidas urgentes en materia financiera), la CNMV es la autoridad competente para la aplicación del Reglamento (UE) n. ${ }^{\circ}$ 596/2014, del Parlamento Europeo y del Consejo, de 16 de abril de 2014, que prevé medidas para estos casos (art. 16). 
(STS 549/1997, 26-4 ${ }^{29}$ ); otra, que entendió de un caso de empleo de violencia con los mismos fines (SAP Coruña 23/2002, de $12-2^{30}$ ); algunas más, que se ocuparon de casos de acuerdos de empresas licitadoras concurrentes a procesos de contratación pública (SSTS 504/2003, de 2-4; 575/2004, de 11-5 y 670/2015, de 30-10 31 ); la del célebre "caso Ibercorp" 32 y, finalmente, la del "caso Titánica"33. Además de estas resoluciones, el "caso BANKIA" dio lugar a una querella por el delito de manipulación de precios $^{34}$.

29 "Caso de las tragaperras", por el que se condenó a varios socios por adquirir 375 máquinas de juego de un determinado tipo sabiendo privilegiadamente algo que ignoraban los posibles competidores en el mercado de las máquinas de juego: que, frente a la prohibición normativa, las máquinas de esa clase iban a ser autorizadas para su colocación en bares, cafeterías y establecimientos similares, lo que determinaría un aumento inmediato de su demanda con correlativo aumento importante de sus precios.

30 Se trata del caso en que se impidió con violencia cargar mejillones en camiones con el fin de alterar sus precios en el mercado.

31 Respectivamente, "caso Ayuntamiento de Getafe", por el que se condenó al concejal de urbanismo y a un contratista que se prestó a la trama (propuesta por el concejal para participar en licitaciones amañadas) como autor de un delito continuado de maquinaciones para alterar el precio de las cosas, entre otros; "caso Ayuntamiento de Torremolinos", en el que se castigó a un concejal y a un contratista por disponer con artificios las licitaciones como autores de los delitos de cohecho y de maquinaciones para alterar el precio de las cosas; y "caso Ayuntamiento de Telde" (o "caso Faycán"), en el que se condenó al acusado porque con su acción de obtener a su favor la adjudicación del contrato que se otorgaba mediante concurso público, entregó importantes cantidades de dinero a los funcionarios encargados de preparar el concurso y la adjudicación, proponiendo él mismo mediante la entrega de pliegos las condiciones concretas en que habría de celebrarse.

32 SAP Madrid 15-2-1999 (dictada en conformidad), que condenó por operaciones de manipulación de precios de valores empleando información privilegiada con fines de enriquecimiento.

33 Caso de manipulación informativa para evitar el desplome del valor de las acciones adquiridas del Banco Popular, por el que fue condenado el administrador único de la mercantil "Titánica" en la SAP Madrid 189/2017, 31-3.

34 Véase la querella presentada por el partido político Unión Progreso y Democracia, que se refiere a los siguientes hechos: "los consejeros directivos y gestores de BANKIA elaboraron y fundieron diversa documentación tanto contable como meramente informativa que arroja una imagen de la sociedad absolutamente irreal, presentando la misma como acreedora de 
Aunque los hechos por los que se dictaron las condenas se dirigieron a distorsionar la formación de los precios con arreglo a las leyes del mercado, a excepción de las dos últimas

una solvencia de la que carecía, con la finalidad de poder salir a bolsa y obtener financiación del mercado en primer lugar y posteriormente intentando mantener a toda costa el precio de cotización y los ratios de solvencia para lo cual no dudaron en manipular la información existente y por ende al propio mercado, alterando el correcto funcionamiento del sistema económico" (AAN JCI 4 4-7-2012). En el AAN JCI 4 10-6-2013, el Ministerio Fiscal se opuso a este delito, diciendo: "En definitiva, la naturaleza de la infracción, la generalización del procedimiento entre las muy distintas entidades emisoras, la razonabilidad del mismo hasta ya entrado el año 2010, el inmediato acatamiento del primer requerimiento de la CNMV en octubre de 2011, la propia ambigüedad del llamado precio razonable y la existencia de una normativa sancionadora específica y propia del ámbito administrativo son circunstancias que no pueden sino llevarnos a concluir la ausencia de tipicidad penal en los hechos descritos en la querella, conclusión que aparece reforzada por nuestra jurisprudencia, siendo ilustrativa en este sentido, entre otras, la STS núm. 600/2007 de 11 de septiembre, en la que, tras referirse al carácter doloso del tipo que nos ocupa y a la necesidad de utilización de engaño, violencia, o intimidación para su comisión, absuelve a los acusados del delito de maquinación para alterar el precio de las cosas por el que eran acusados por mantener la cotización de la sociedad Prima Inmobiliaria S.A. durante dos años consecutivos, al entender que, el plan de los acusados no tenía, de modo evidente, el objetivo de alterar el precio de las cosas (como es inherente al tipo penal cuya indebida inaplicación se denuncia), sino el de eludir la normativa vigente siendo, en definitiva, la finalidad perseguida el eludir los controles legales, pero no alterar los precios resultantes de la libre concurrencia en el mercado bursátil." Sobre ello, véase, crítico, Palma Herrera, considerando que "en el momento en que el valor de estos productos comienza a caer como consecuencia del acuerdo de Basilea III y de la crisis financiera, este sistema deja de ser un mecanismo que busca la agilidad en las transacciones para convertirse en un medio dirigido a mantener artificialmente unos precios que permitieran a su vez deshacerse del producto a quien quería hacerlo a costa de colocarlo a inversores a un precio muy por encima del real" [en "Sobre la posible responsabilidad penal de Bankia, BFA y algunos de sus administradores por el tema de las preferentes", en Miranda Serrano, L.M . (Dir.): La protección de los consumidores en tiempos de cambio. Ponencias y Comunicaciones del XIII Congreso de la Asociación Sainz de Andino, Ed. Iustel, Madrid, 2015, p. 548]. En parecidos términos, Cancio Meliá, M.: "Caso BANKIA/Preferentes: Fraude masivo y Derecho Penal", en Corcoy Bidasolo, M./Gómez Martín, V. (Dirs.): Fraude a consumidores y Derecho penal. Fundamentos y talleres de leading cases, Ed. B. de f, Montevideo-Buenos Aires, 2016, pp. 409-436. 
resoluciones condenatorias citadas, ninguna representa adecuadamente, en mi opinión, la idoneidad que deben poseer como atentados de alcance contra la función del mercado conforme a una lectura teleológica del significado de los delitos de manipulación de mercado ${ }^{35}$.

Así, pues, de la corta experiencia jurisprudencial sobre los delitos de manipulación de precios puede concluirse que han llegado muy pocos casos ante los órganos jurisdiccionales, y que los jueces y tribunales, aunque han encontrado obstáculos a su castigo, también han hallado en estas figuras posibilidades de sanción de conductas que, desde mi punto de vista, resultan de dudoso encaje en sus injustos típicos.

\section{Clases de conductas típicas de manipulación de mercado. Las nuevas exigencias de la Directiva 2014/57}

Los delitos de manipulación de precios se han mantenido muy estables en su formulación original hasta el Código Penal de $1995^{36}$. Este Texto introdujo importantes novedades que se

35 El primer caso, sobre las máquinas de juego (STS 549/1997), porque en un escenario como el que se dio, de autorización administrativa de unas máquinas que habían estado prohibidas hasta la fecha, la incidencia de las conductas de acopio habría requerido el examen de su idoneidad concreta, pues, como se reconoce en la sentencia dicha autorización "determinaría un aumento inmediato de su demanda con correlativo aumento importante de sus precios". En el segundo caso, del ataque a los mejilloneros (SAP Coruña 23/2002), la conducta ofrecía, en principio, dificultades para reunir el significado típico como delito de intento de alteración de precios, fundamentalmente, al tratarse de una operación muy concreta cuya idoneidad para afectar a los precios dependía del ámbito del mercado al que estaba dirigido a concurrir el producto. Y, por último, con respecto a los pronunciamientos correspondientes a los hechos de connivencia entre empresas y funcionarios para conseguir la adjudicación de contratos con la Administración (SSTS 504/2003 y 575/2004), la dificultad tiene que ver con el ámbito de "mercado" que está en juego, que en estos casos se ciñe a los correspondientes procesos de contratación pública.

36 En efecto, desde el texto original del art. 451 del Código de 1848, la descripción de su conducta típica se conservó sin cambios hasta la Ley 44/1971, de 
plasmaron, sobre todo, en los medios comisivos ("difundiendo noticias falsas, empleando violencia, amenaza o engaño, o utilizando información privilegiada"), pero siguió manteniendo el hecho típico tal y como lo había adelantado la Ley de 1971 (es decir, bastando el intento de alterar los precios). Los principales cambios llegaron, primero, con la L.O. 5/2010 y, recientemente, con la L.O. 1/2019, ambas focalizadas en el mercado financiero. La primera gran reforma de 2010 afectó fundamentalmente a las conductas típicas y, en cuanto a los objetos, incorporó los "instrumentos financieros", quedando así, muy resumidamente, el cuadro de las conductas típicas de manipulación de mercado:

— tentativa de alteración de precios (art. 284. $1^{\circ}$ ),

— difusión de noticias o rumores para alterar o preservar el precio de cotización, obteniendo un beneficio o causando un perjuicio superior a $300.000 \mathrm{C}\left(\operatorname{art} .284 .2^{\circ}\right) \mathrm{y}$

- realización de transacciones, dación de órdenes de operación o aseguramiento de posición dominante utilizando información privilegiada para alterar el precio de valores o instrumentos financieros (art. 284. $3^{\circ}$ )

Los comportamientos de manipulación de mercado ${ }^{37}$ que la Directiva 2014/57 obligó a castigar penalmente son los siguientes $^{38}$ :

- transmisión de señales falsas o engañosas en cuanto a la oferta, a la demanda o al precio de instrumentos financie-

15 de noviembre, sobre reforma del Código Penal, como conseguir alterar los precios esparciendo falsos rumores o usando de cualquier otro artificio. La Ley de 1971 incluyó también la referencia expresa a los "títulos o valores" como objetos cuyo precio podía ser alterado típicamente (hasta entonces, todos los códigos penales españoles aludían a "mercancías, acciones, rentas públicas o privadas o cualesquiera otras cosas que fueren objeto de contratación").

37 En sentido estricto; dejando aparte las operaciones con información privilegiada, tal y como diferencia la Directiva (passim).

38 Se prescinde aquí de detalles de las conductas que en este momento se consideran innecesarios por razones expositivas. Véanse más adelante las consideraciones acerca de las conductas recogidas en esta Directiva. 
ros o contratos de contado de materias primas referidos a ellos (ejecutando una operación, dando una orden de negociación, difundiendo información o mediante cualquier otra conducta) [art. $5.2, \mathrm{a}), \mathrm{i})$; c) y d)];

- fijación en un nivel anormal o artificial del precio de uno o varios instrumentos financieros o contratos de contado de materias primas referidos a ellos, de cualquier modo (ejecutando una operación, dando una orden de negociación, difundiendo información o mediante cualquier otra conducta) [art. 5.2, a), ii)];

- alteración del precio de instrumentos financieros o contratos de contado de materias primas referidos a ellos (ejecutando una operación, dando una orden de negociación o con cualquier actividad o conducta mediante cualquier forma de engaño o artificio [art. 5.2, b)];

- manipulación del cálculo de un indice de referencia (mediante la transmisión de información falsa o engañosa, el suministro de datos falsos engañosos o cualquier otra conducta) [(art. 5.2, d)].

La Directiva también ordenó sancionar penalmente la incitación a cometer cualquiera de estas infracciones, así como la tentativa y la complicidad (art. 6). Y, como ya destaqué, impuso que las penas privativas de libertad tuvieran, al menos, una duración de cuatro años en su límite máximo.

Ahora bien, como también había avanzado, el uso de las sanciones penales solamente se exige para los casos graves (art. 5.1), calificación que se reserva para aquellas operaciones en las que "sea elevado el impacto en la integridad del mercado, el beneficio derivado real o potencial o las pérdidas evitadas, la importancia del daño causado al mercado o el nivel de la alteración del valor del instrumento financiero o del contrato de contado sobre materias primas o el importe de los fondos utilizados inicialmente, entre otros, o cuando la manipulación se haya cometido por una persona empleada o que trabaje en el sector financiero o en una autoridad supervisora o reguladora" [Conside- 
rando (12) $]^{39}$. No obstante, la Directiva permite expresamente a los Estados miembros someter también a castigos penales otros casos (como el que ejemplifica, de manipulaciones del mercado cometidas temerariamente o por negligencia grave $\mathrm{e}^{40}$ ).

Por lo demás, esta norma europea deberá aplicarse teniendo en cuenta el marco jurídico que completó el Reglamento 596/2014 del Parlamento y del Consejo de 16 de abril de 2014 sobre abuso de mercado, un instrumento -de aplicabilidad directa en los Estados miembros- cuyo objeto es establecer un régimen y una interpretación uniformes en el marco de la Unión Europea sobre el abuso de mercado (en sus manifestaciones de utilización y comunicación de información privilegiada y de manipulación de mercado). Para ello, entre otras líneas para lograr la armonización, el Reglamento define las infracciones que quedan reservadas (en principio, como veremos), al ámbito del Derecho administrativo de los Estados miembros.

El nuevo régimen obligaba a revisar a fondo la disciplina general de abuso de mercado en nuestro país. Con respecto a las normas penales, tanto por el diferente contenido -objetivo y subjetivo- de varios de los supuestos que contempló la Directiva, como por la duración mínima que impuso para el límite máximo de la pena de privación de libertad, era imprescindible modificar el artículo 284.

Además, la Directiva impuso la responsabilidad de las personas jurídicas, pero dejando a criterio de los Estados el exigir una responsabilidad penal o administrativa. Nuestro Código Penal contemplaba ya, a la entrada en vigor de la Directiva, dicha responsabilidad tanto para los delitos de manipulación de precios como para el uso de información privilegiada (aunque

39 Llama la atención que esta disposición no se halle en el texto propiamente normativo y que figure entre los "considerandos", utilizados generalmente para justificar la parte dispositiva de las directivas. Pero su vocación normativa es inequívoca, al decir, "A efectos de la presente Directiva, la manipulación de mercado se debe considerar grave en casos en que..."

40 Véanse los Considerandos (20) y (21). 
la LO 5/2010 no comprendió los delitos del art. 284, que fueron incorporados más tarde al art. $288 \mathrm{CP}^{41}$ ).

Con todo, sin embargo, la decidida apuesta de las directrices europeas por la intervención penal plantea dudas acerca del respeto al mandato de subsidiariedad del Derecho penal por las autoridades europeas en esta materia a la vista de la escasa aplicación de las disposiciones precedentes de naturaleza administrativa $^{42}$. Y el legislador español tampoco ha explotado las alternativas que la Unión Europea dejaba abiertas para una intervención penal mínima, destinando las conductas de menor gravedad al ámbito del Derecho administrativo sancionador.

Pero vayamos al detalle de las concretas necesidades de adaptación de la ley penal española al nuevo régimen establecido por la Unión Europea. Al respecto, dejando ahora a un lado la necesidad de ampliar la penalidad, si se compara la regulación que resultó de la reforma de 2010 con las obligaciones impuestas por la Directiva, se observa que algunas de las exigencias del Código Penal limitaban la pretendida intervención punitiva, bien por la no previsión de la conducta, bien por la exigencia de unos determinados medios (como la información privilegiada, en el art. $284.3^{\circ}$ ) o debido al requisito de la obtención de un determinado beneficio o del ocasionamiento de un determinado perjuicio (art. $284.2^{\circ}$ ).

En el cuadro siguiente se recogen esquemáticamente, por una parte, las infracciones que la Directiva de abuso de mercado ordenó castigar penalmente y, por otra, las correspondientes figuras del Código Penal antes de la reforma de 2019.

41 A través de la Disposición final segunda de la LO 3/2011, por la que se modifica la LO 5/1985, del Régimen Electoral General.

42 Véase la nota 10 
Figura 1. Comparación de los delitos de manipulación de mercado de la Directiva 2014/57 y del Código Penal tras la L.O. 5/2010, de modificación del Código Penal

Directiva 2014/57/UE [art. 5.2, a), b), c) y d)] ${ }^{43}$

Código penal (art. 284, $1^{\circ}, 2^{\circ}$ y $3^{\circ}$ )

\begin{tabular}{|c|c|c|}
\hline $\begin{array}{l}\text { transmitir señales } \\
\text { falsas/engañosas } \\
{[a), \text { i) y c)] }}\end{array}$ & $\begin{array}{l}\text { ejecutando una operación }[\mathrm{a}), \mathrm{i})] \\
\text { dando una orden de negociación } \\
[\mathrm{a}), \mathrm{i})] \\
\cdot \text { difundiendo información }[\mathrm{c})] \\
\text { mediante cualquier otra conducta } \\
[\mathrm{a}), \mathrm{i})]\end{array}$ & $\begin{array}{l}\approx \text { difundir noticias/ } \\
\text { rumores }\left(2^{\circ}\right) \\
\approx \text { proporcionar indicios } \\
\text { engañosos }\left(3^{\circ}\right)\end{array}$ \\
\hline \multirow[t]{2}{*}{$\begin{array}{l}\text { fijar precios en } \\
\text { un nivel anormal o } \\
\text { artificial / afectar } \\
\text { a precios [a), ii), } \\
\text { b) y c)] }\end{array}$} & $\begin{array}{l}\text { - ejecutando una operación [a), ii) } \\
\text { y b)] } \\
\text { dando una orden de negociación [»] } \\
\text { difundiendo información [c)] } \\
\text { mediante cualquier otra conducta } \\
\text { [a), ii) y b): mediante mecanismos } \\
\text { ficticios o cualquier forma de engaño } \\
\text { o artificio] }\end{array}$ & $\begin{array}{l}\approx \text { intentar alterar precios } \\
\left(1^{\circ}\right)\end{array}$ \\
\hline & & $\begin{array}{l}\text { asegurar una posición } \\
\text { dominante }\left(3^{\circ}\right)\end{array}$ \\
\hline $\begin{array}{l}\text { manipular el } \\
\text { cálculo de un índice } \\
\text { de referencia [d)] }\end{array}$ & $\begin{array}{l}\text { - transmitiendo información falsa/ } \\
\text { engañosa }[\mathrm{d})] \\
\cdot \text { suministrando datos falsos/ } \\
\text { engañosos [d)] } \\
\cdot \text { mediante cualquier otra conducta } \\
[\mathrm{d})]\end{array}$ & $\varnothing$ \\
\hline
\end{tabular}

Como puede apreciarse, la relación de unas y otras conductas resulta muy forzada, porque alguno de los supuestos de la Directiva no podía ser reconducido a ninguno de los delitos del Código Penal y ninguno de estos era exactamente asimilable a aquellos. Pero no solo por el modo en que se describía la conducta, sino porque incluso allí donde se aproximaba (p. ej., en el supuesto de la difusión de noticias o rumores), el Código Penal incluía exigencias ajenas a la nueva regulación europea que impedían cumplir con la Directiva porque restringían la in-

43 Las conductas punibles se presentan en primer lugar (primera columna) atendiendo a los resultados que deben alcanzar en sus formas consumadas (trasmitir señales falsas o engañosas, fijar en un nivel anormal o artificial el precio, etc.) y, en segundo lugar (segunda columna), según sus modos de comisión (ejecutar una operación, dar una orden de negociación, etc.), sin perjuicio de las consideraciones que se harán en el texto. 
tervención penal (siguiendo con el mismo ejemplo, la necesidad de un beneficio o perjuicio de un determinado importe).

Así, si la difusión de noticias o rumores (art. $284.2^{\circ}$ ) podía relacionarse con la transmisión de señales falsas o engañosas, resultaba estrecha para abarcar "señales" no constituidas por mensajes de la naturaleza prevista legalmente, es decir, "datos económicos total o parcialmente falsos" (como, por ejemplo, señales dadas a través de operaciones u órdenes de negociación).

De forma similar, el proporcionar indicios engañosos sobre la oferta, la demanda o el precio de valores o instrumentos financieros (art. $284.3^{\circ}$ ), que también podía relacionarse con la transmisión de señales falsas o engañosas de la Directiva, se limitaba en el Código Penal a acciones llevadas a cabo utilizando información privilegiada. Por su parte, las alteraciones de precios (fijación de precios en un nivel anormal o artificial o afectación de precios) solamente era posible asimilarlas muy fragmentariamente al delito de intento de alteración de precios (art. 284.1 ${ }^{\circ}$ ), que únicamente estaba en condiciones de cubrir determinadas tentativas (también punibles, como ya he señalado, a tenor de la Directiva). A todo lo anterior hay que añadir que los objetos de referencia de los precios resultaban claramente insuficientes en comparación con los incluidos por la Directiva (contratos de contado sobre materias primas e índices de referencia, en particular), lo que claramente determinaba la atipicidad de otros supuestos (como la manipulación del cálculo de índices de referencia). De este modo, a la vista de la Directiva, no había más remedio que adaptar el Código Penal en esta materia, como reconoce el Preámbulo de la L.O. 1/2019, por la que se modifica el Código Penal.

Tras la reforma, las modalidades comisivas del Código Penal son, resumidamente ${ }^{44}$, las siguientes:

44 De nuevo, prescindiendo aquí de detalles de las conductas por razones expositivas. 
- alteración de precios de productos, mercancías, instrumentos financieros, contratos de contado sobre materias primas relacionadas con ellos, índices de referencia, servicios o cualesquiera otras cosas muebles o inmuebles que sean objeto de contratación mediante violencia, amenaza, engaño o cualquier otro artificio (art. 284.1.1 ${ }^{\circ}$ );

- difusión de noticias o rumores o transmisión de señales falsas o engañosas para incidir en los precios de instrumentos financieros o de contratos de materias primas relacionados con productos financieros, o índices de referencia (art. 284.1.2 ${ }^{\circ}$ ) y

- suministro de indicios falsos o engañosos sobre la oferta, la demanda o el precio de un instrumento financiero, un contrato de contado sobre materias primas relacionado o índices de referencia, o aseguramiento, utilizando la misma información, por sí o en concierto con otros, de una posición dominante en el mercado (art. 284.1.3 ${ }^{\circ}$ ).

Como se ve, pues, se ha modificado sustancialmente tanto la estructura de los delitos del artículo 284 , como sus conductas, sus medios comisivos y los objetos materiales de naturaleza financiera. Además, la supresión de la exigencia del uso de información privilegiada ha modificado también las relaciones de las figuras recogidas en esta disposición con las del artículo 285.

Por lo que se refiere a los tipos agravados (art. 284.2 y 3 ), cuyas particularidades se verán también más adelante, atienden a los criterios de la habitualidad en las prácticas abusivas y la "notoria importancia" del beneficio, o de la pérdida evitada o del perjuicio causado, o la condición profesional del agente.

Y unas cláusulas finales, comunes a los delitos de manipulación de mercado y a los que consisten en operaciones con información privilegiada, disponen la extensión del castigo a supuestos en los que las conductas o los objetos de referencia de 
los precios estén previstos en adelante en el Derecho español o europeo, así como el castigo de los actos preparatorios (arts. 285 ter y quáter).

Seguidamente, se expondrán con mayor detalle todas las novedades.

\section{Novedades con respecto al delito de alteración de precios (art. 284.1.1 ${ }^{\circ}$ )}

La figura delictiva menos afectada por la reforma ha sido la más señera, por su tradición, de este ámbito. Se trata del delito de alteración de precios, que ha visto modificada la propia conducta típica (pero solo con respecto al momento decisivo de la consumación del delito), los medios comisivos y los objetos a los que pueden hacer referencia los precios.

Tras la reforma de 2019, el artículo $284.1 .1^{\circ}$ castiga las alteraciones de precios conseguidas mediante violencia, amenaza, engaño o cualquier otro artificio. La regulación anterior sancionaba el mero intento de alterar los precios por medio de violencia, amenaza o engaño. Con la nueva exigencia de la efectiva alteración se recupera la forma típica que quedó abandonada en la reforma de $1971^{45}$. De modo que, a diferencia de la regulación precedente, el momento consumativo ya no se anticipa al simple intento, sino que ahora es necesario que se consiga la alteración.

Esta reformulación de la conducta típica, desde luego, dota de mayor base material al injusto típico (como ha planteado un sector de la doctrina ${ }^{46}$ ), sin embargo, en la práctica, la prueba de la alteración presentará dificultades porque no siempre será sencillo comprobar la incidencia causal concreta de la aplicación

45 Sobre ello, véase García-Pablos: "Sobre la figura del delito para alterar los precios (naturales) de las cosas", cit., pp. 237 y 238.

46 Véase, ya, García-Pablos, con argumentos de intervención mínima, en "Sobre la figura del delito para alterar los precios (naturales) de las cosas", cit., pp. 237 y 238. También, Paredes Castañón en "Problemas de tipicidad en las conductas de manipulación de precios de los mercados de valores", cit., pp. 20 y $25-29$. 
del medio comisivo con el resultado típico. A propósito de esto, y sin perjuicio de ulteriores observaciones sobre la penalidad, aunque la pena pecuniaria, en una de sus alternativas (multa por el sistema proporcional), depende del beneficio obtenido o favorecido, o de los perjuicios evitados, la consumación del delito no requiere la obtención del uno, ni la evitación de los otros, pues estos son independientes, hasta cierto punto, de la alteración, en la medida en que dependen de algo sin trascendencia típica, como es el que se ejecute la desinversión o la inversión.

Por lo demás, la problemática que, bajo el régimen anterior de estos delitos, llevó a la doctrina a ofrecer criterios para acotar los intentos de alteración de precios típicos (una cierta suficiencia en relación con el fin perseguido, esto es, un mínimo de idoneidad ${ }^{47}$ ), pueden reconducirse tras la reforma al ámbito de la imputación objetiva.

A los medios comisivos que se habían conservado desde el Código Penal de 1995 ("violencia, amenaza y engaño") la reforma de 2019 ha añadido "cualquier otro artificio"48. Pese a que - particularmente, las tres primeras- son formas de actuar generalmente consideradas muy significativas en términos de injusto, la doctrina había planteado que no son necesariamente las más graves y usuales para afectar al bien jurídico protegido ${ }^{49}$ y había abogado por incluir, de lege ferenda, los acuerdos colusorios y los abusos de posición dominante ${ }^{50}$. Ciertamente, a la vista del nuevo medio típico ("o cualquier otro artificio"), algunas de estas actuaciones podrían quedar bajo el artículo 284.1.1 ${ }^{051}$, como

47 Así, García-Pablos, exigiendo una capacidad intrínseca o gravedad (en $o p$. cit., p. 229).

48 Esta fórmula recuerda a la cláusula abierta que llegó hasta el Código de 1973, que concluía diciendo "o usando cualquier otra maquinación" (art. 540).

49 Así, Paredes Castañón (en "Problemas de tipicidad en las conductas de manipulación de precios de los mercados de valores", cit., passim) o Estrada i Cuadras (en "Presente y futuro del delito de alteración de precios (art. 284 Cp)", cit., p. 10).

50 Véase Estrada i Cuadras: op. cit., p. 10.

51 Véase, ya, Boix Reig: "Las prácticas restrictivas de la competencia en el Proyecto de Código Penal de 1980", cit., p. 40. 
otras que tuvieran un potencial para alterar los precios análogo al de los demás medios explicitados en el párrafo, tanto desde el punto de vista fáctico como valorativo, porque la disyunción ("o") no constituye una alternativa más, sino que debe interpretarse como una equiparación en términos de su significado valorativo. Así, singularmente, las manipulaciones informáticas, sin excluir otras manipulaciones de hecho, como adulteraciones de productos con fines especulativos.

El objeto sobre el que debe recaer la conducta son los precios que habrían de resultar de la libre concurrencia de "productos, mercancías, instrumentos financieros, contratos de contado sobre materias primas relacionadas con ellos, índices de referencia, servicios o cualesquiera otras cosas muebles o inmuebles que sean objeto de contratación". A pesar de la amplitud de la última referencia a "cualesquiera otras cosas muebles o inmuebles" (que también se encontraba en la regulación precedente), la L.O. 1/2019, en consonancia con la Directiva 2014/57, ha añadido como novedad la mención expresa a "contratos de contado sobre materias primas relacionadas con ellos" y a "índices de referencia". Ambos objetos son contemplados entre las "definiciones" que establece la Directiva (art. 2); aunque, como veremos, son remitidos para su definición a lo dispuesto en el Reglamento 596/2014, sobre abuso de mercado. De este modo, dentro de los límites que impone el principio de legalidad y sin perjuicio de la orientación que corresponde a la interpretación en el marco del Derecho penal conforme a sus fines, el significado de los objetos de naturaleza financiera a los que se refieren los precios deberá extraerse, en virtud del principio de interpretación conforme a las directivas, de tales definiciones.

La referencia a los contratos de contado sobre materias primas relacionados con instrumentos financieros es la más concreta de cuantas contiene el precepto para aludir a los objetos de los precios y también es la más difícilmente asequible por su naturaleza particularmente técnica (aunque esta naturaleza también caracteriza, desde luego, a los "instrumentos financieros"). $\mathrm{Su}$ definición se remite por la Directiva (art. 2.2) al Reglamento 
$596 / 2014$, donde se señala que son "contratos negociados en un mercado de contado para el suministro de una materia prima que se entrega tan pronto se liquida la operación, así como el contrato para el suministro de una materia prima que no tiene la consideración de instrumento financiero, incluyendo el contrato con entrega aplazada" (art. 3.1; el "mercado de contado" es definido en el art. 3.1. del mismo Reglamento).

La importancia de estos contratos como objetos financieros se basa en que los precios de ciertos productos sometidos a estacionalidad o concentración de la demanda, como productos agrícolas o energéticos, se aseguran a menudo por medio de instrumentos financieros a plazo (como los contratos de futuros o de opción) frente a sus posibles variaciones. Estos instrumentos constituyen productos financieros "derivados", ya que se hacen depender de otras referencias, como en este caso, los precios del mercado al contado sobre materias primas, que actúan como "activos subyacentes" 52 .

No obstante, la alusión expresa y en concreto a estos contratos contrasta con la amplitud de las demás referencias del precepto. Pero la razón del detalle en el caso de las materias primas se halla en el propósito del legislador de castigar no solo las manipulaciones directas de los precios de cualesquiera cosas que sean objeto de contratación, sino también las que resultan de actuaciones indirectas sobre los mismos, atacando a las referencias que les sirven de base para su comportamiento y que no quedan abarcadas por la alusión a los "instrumentos financieros" (que no los incluye ${ }^{53}$ ). Aunque el detalle que se observa con res-

52 Fernández Pérez, N.: "La contratación en los mercados secundarios oficiales", en Campuzano, A.B./ Conlledo Lantero, F./Palomo Zurdo, R.J. (Dirs.): Los mercados financieros, $2^{\mathrm{a}}$. ed., Ed. Tirant lo Blanch, Valencia, 2017, pp. 783-785.

53 Véanse la definición extensiva de los "instrumentos financieros" en el anexo I, sección C, de la Directiva 2014/65/UE del Parlamento Europeo y del Consejo de 15 de mayo de 2014, relativa a los mercados de instrumentos financieros y por la que se modifican la Directiva 2002/92/CE y la Directiva 2011/61/UE. También, la que proporciona el anexo del Real Decreto Legislativo $4 / 2015$, de 23 de octubre, por el que se aprueba el texto refundido de la Ley del Mercado de Valores. 
pecto a los "contratos de contado sobre materias primas" puede contrastar con el silencio en el caso de otros posibles activos subyacentes a productos derivados (como divisas, tipos de interés o rendimientos, etc.), estos quizá podrían quedar abarcados por las menciones expresas a los "instrumentos financieros" o a los "índices de referencia", que dotan a la relación legal de unas amplias posibilidades de actualización ante la creciente sofisticación de los productos financieros.

El objeto constituido por "índices de referencia" resulta de una enorme vaguedad. Se trata de cifras, relaciones, series o escalas numéricas que sirven como medida para establecer un precio. Pueden ser muy variados: índice de tipos de interés del mercado interbancario (determinantes de los precios de los préstamos bancarios), índices de cotización de valores y otros instrumentos financieros, de divisas, índices de referencia financieros de transición climática ${ }^{54}$, etc. Para su definición, de nuevo, la Directiva 2014/57 remite al Reglamento 596/2014, donde se establece que un índice de referencia es "cualquier tasa, índice o cifra, puesto a disposición del público o publicado, que se determina de forma periódica o regular, mediante la aplicación de una fórmula o sobre la base del valor de uno o varios activos subyacentes o precios, incluyendo precios estimados, tipos de interés $\mathrm{u}$ otros valores reales o estimados, o a datos de estudios, y que se utiliza como referencia para determinar la cantidad pagadera por un instrumento financiero o el valor de un instrumento financiero" (art. 2.29). Pero, como puede apreciarse, el concepto legal es amplísimo.

Además de servir como instrumento fundamental para conocer los precios de diversos instrumentos financieros, prin-

54 Se trata de una nueva categoría de índices de referencia financieros de bajo impacto medioambiental que ha impulsado recientemente la Unión Europea mediante la Resolución legislativa del Parlamento Europeo, de 26 de marzo de 2019, sobre la propuesta de Reglamento del Parlamento Europeo y del Consejo por el que se modifica el Reglamento (UE) 2016/1011 en lo relativo a los índices de referencia de bajo impacto carbónico y de impacto carbónico positivo. 
cipalmente valores negociables, los índices pueden constituir, al igual que las materias primas, un elemento subyacente a un contrato de derivados.

Su importancia, pues, es indudable. Y la exposición de los mercados a los riesgos de su manipulación ha sido constatada a través de algunos casos muy alarmantes, sobre todo, atendiendo a las dinámicas y al alcance de las operativas descubiertas ${ }^{55}$.

En suma, el resultado de la modificación legal de este apartado del artículo 284.1 es un tipo de extraordinaria amplitud debida, fundamentalmente, a la abierta fórmula de cierre de los medios comisivos, que dota al precepto de una función subsidiaria con respecto a las restantes modalidades típicas que requieran la efectiva alteración de precios (véase el art. 284.1.2 $2^{\circ}{ }^{56}$.

55 Sobre los casos de manipulación entre los años 1991-2012 de los índices de referencia del LIBOR y EURIBOR (en los que se basa la fijación del precio de las hipotecas y otros muchos productos financieros) véase Luchtman, M.J.J.P./Vervaele, J.A.E.: "Aplicación del régimen de abuso de mercado (operaciones con información privilegiada y la manipulación del mercado): ¿Hacia un modelo integrador de la aplicación de la ley penal y administrativa en la UE?", en Pérez Cepeda, A.I. (Dir.): Política criminal ante el reto de la delincuencia transnacional, Ed. Universidad de Salamanca-Tirant lo Blanch, Salamanca, Valencia, 2016, pp. 759-762. En mayo de 2019 la Comisión Europea sancionó con 1.000 millones de euros a cinco bancos que habían intervenido en operaciones de manipulación del precio de divisas en el mercado conocido como FOREX (Barclays, Royal Banc of Scotland, Citygroup, JPMorgan y Mitsubishi UFJ Financial Group; el suizo UBS también participó, pero se benefició por su colaboración con las autoridades). Brokers de estas entidades intercambiaban información a través de chats para decidir el momento y la cantidad de operaciones con divisas, afectando así a la cotización de 11 divisas. Véase sobre otros casos similares Pérez Guerra, M.: "El abuso de mercado: «business as usual» en las operaciones de derivados", en La Ley, núm. 4677, 2015.

56 Coincido en esto con Feijoo Sánchez: "Los delitos de manipulación del precio de cotización de un instrumento financiero del art. 284 CP tras la LO 1/2019", cit., p. 19. 


\section{Novedades con respecto al delito de manipulación infor- mativa (art. 284.1.2 ${ }^{\circ}$ )}

El nuevo artículo $284.1 .2^{\circ}$ contiene una figura típica en la que se reconoce la versión derogada de la difusión lucrativa de informaciones falsas (art. 284.2. ${ }^{\circ}$ ), pero la nueva redacción la modifica y amplía en una disposición que como vamos a ver resulta mucho más compleja. Los cambios fundamentales afectan sobre todo a los objetos de los precios, a los medios comisivos $\mathrm{y}$-lo que es fundamental-a las nuevas condiciones establecidas para el castigo de estas conductas.

Tras la reforma, se sanciona a quien: "por sí, de manera directa o indirecta o a través de un medio de comunicación, por medio de internet o mediante el uso de tecnologías de la información y la comunicación, o por cualquier otro medio, difundieren noticias o rumores o transmitieren señales falsas o engañosas sobre personas o empresas, ofreciendo a sabiendas datos económicos total o parcialmente falsos con el fin de alterar o preservar el precio de cotización de un instrumento financiero o un contrato de contado sobre materias primas relacionado o de manipular el cálculo de un índice de referencia, cuando obtuvieran, para sí o para tercero, un beneficio, siempre que concurra alguna de las siguientes circunstancias: a) que dicho beneficio fuera superior a doscientos cincuenta mil euros o se causara un perjuicio de idéntica cantidad; b) que el importe de los fondos empleados fuera superior a dos millones de euros; c) que se causara un grave impacto en la integridad del mercado".

La interpretación del precepto es una tarea difícil porque la conducta típica es descrita como una amalgama de medios, modos y resultados que deben alinearse con el fin de alterar o preservar los correspondientes precios.

El comportamiento, para ser típico, habrá de dar lugar a la presentación de datos económicos falsos mediante lo que parecen dos modos alternativos de ofrecer datos económicos total o parcialmente falsos: difundiendo noticias o rumores o transmitiendo señales falsas o engañosas sobre personas o empresas. 
La gravedad de esta clase de conductas reside en que la diseminación de tal información, como advierten las normas europeas, puede tener una repercusión significativa en los precios de los instrumentos financieros en un período relativamente corto.

A la modalidad precedente que consiste en difundir noticias o rumores acompaña literalmente, pues, a partir de la reforma, la alternativa de "transmitir señales falsas o engañosas". Se ha observado por Feijoo Sánchez, sin embargo, que esta última no puede constituir una conducta alternativa, sino que es más bien la expresión del efecto que comporta la acción de difundir las noticias o los rumores; de modo que la expresión legal debería interpretarse restrictivamente en el sentido de "difundir noticias o rumores $[\ldots]$ transmitiendo señales falsas o engañosas" ${ }^{\prime 57}$. Las razones para ello se basan, por una parte, en la relación de accesoriedad del Derecho penal estatal con respecto al Derecho de la Unión Europea, que condiciona la interpretación de las normas penales conforme a las valoraciones básicas del orden primario extrapena $l^{58}$. Y, por otra parte, en argumentos que derivarían de inconsistencias de las propias referencias legales a la transmisión de señales falsas o engañosas en los dos contextos de las manipulaciones informativas y operativas, respectivamente recogidas en los apartados $2^{\circ}$ y $3^{\circ}$ del artículo 284.1. Estas se concretarían en que una misma conducta (la transmisión de señales) se defina al mismo tiempo como dos modalidades de manipulación diferentes ${ }^{59}$; así como en que la finalidad de la re-

57 Véase la argumentada propuesta que realiza en "Los delitos de manipulación del precio de cotización de un instrumento financiero del art. $284 \mathrm{CP}$ tras la LO 1/2019", cit., pp. 6-9.

58 Feijoo Sánchez: op. cit., p. 5.

59 Op. cit., pp. 6-7. Feijoo lo explica así: "Si se entendiera que la reforma ha pretendido equiparar la transmisión de señales falsas a la difusión de noticias o rumores, en las manipulaciones informativas el delito consistiría en transmitir señales falsas o engañosas debiendo ser entendida la difusión de noticias o rumores falsos como una forma específica de llevar a cabo dicha conducta. Pero, a su vez, la transmisión de señales falsas o engañosas constituiría también la modalidad de manipulaciones operativas que se lleva acabo operando en el mercado o dando órdenes para operar en el mercado" (p. 7). 
forma fue la incorporación de la Directiva al Derecho interno $\mathrm{y}$, por lo tanto, las modalidades típicas resultantes de la misma deben ajustarse, ante los inconvenientes advertidos, a lo previsto en la norma europea ${ }^{60}$. La lectura que propone Feijoo es, además, más restrictiva que la que deriva de la lectura del texto legal, al convertir la exigencia de transmisión de señales falsas o engañosas, no en una alternativa, sino en un componente de la conducta definidor de su idoneidad lesiva para la integridad del mercado ${ }^{61}$.

Como el propio autor reconoce, la interpretación ofrecida no está libre de inconvenientes, porque la reforma impide "una solución limpia", dado que la elaboración del texto presentó serias carencias técnicas que han terminado afectando al producto final ${ }^{62}$, pero por razones sistemáticas y teleológicas se presenta como la preferible, buscando la compatibilidad con la Directiva ${ }^{63}$.

Personalmente, coincido con el enfoque y las apreciaciones de Feijoo. Sin embargo, entiendo que también cabe ver las cosas de un modo algo diferente con un resultado similar al propuesto. A mi modo de ver, la letra del Código permite entender que las conductas típicas pueden ser descritas de otro modo, y no necesariamente viendo en la transmisión de señales una conducta autónoma. Así, cabe considerar que el núcleo de la conducta típica del artículo $284.11^{\circ}$. está constituido por el hecho de ofrecer a sabiendas datos económicos total o parcialmente falsos. Así, la difusión de noticias o rumores, por un lado y, por otro, la transmisión de señales falsas o engañosas constituirían dos modos diferentes de cometer el delito.

Esta interpretación respeta más fielmente la letra de la ley, no pierde la exigencia objetiva de idoneidad, pues es ínsita a la propia conducta, y no cierra la posibilidad de abarcar modos comisivos a través de mensajes ("señales") que no consti-

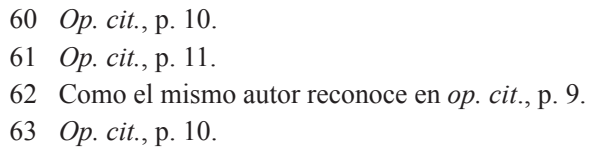


tuyen noticias ni rumores. Aunque, claro está, también tiene el coste que supone aproximar las manipulaciones "informativas" del apartado $2^{\circ}$ a las manipulaciones "operativas" del $3^{\text {o64 }}$, pues aquellas ya no se ceñirían a maniobras basadas en el manejo de noticias o rumores (y aunque esto también ofrecería el problema de conciliar la referencia a que las "señales" se refieran "a personas o empresas").

En cuanto a su significado, además, la transferencia de señales falsas o engañosas, aunque puede ser entendida como "comunicar", en el contexto sistemático del precepto posee un significado más cercano a "hacer llegar", "aportar" o "incorporar" al mercado tales señales, introduciendo así una información que altera las variables normales que juegan en la fijación de los precios. Qué deba entenderse por "señales" es algo, desde luego, fundamental aquí, pero no se define en las normas europeas, precisamente, por el carácter pretendidamente abierto de la expresión, que puede abarcar signos muy diversos. De nuevo, la exigencia legal a que sean "sobre personas o empresas", limita las posibilidades, pero no me parece que lo haga hasta el punto de confundir esta modalidad con la de difusión de noticias o rumores. Para desentrañar el significado de las señales pueden ser orientativos los "Indicadores de manipulaciones relativas a señales falsas o engañosas y con la fijación de los precios" que ofrece el Reglamento 596/2014 en su Anexo I ${ }^{65}$.

Por lo que se refiere a las formas de comisión del delito, por más que la conducta sea activa en cualquiera de sus modalidades, puede reunir los caracteres típicos por omitir información que debe proporcionarse conforme a la normativa que regula el mercado. De modo que sería posible articular una responsabili-

64 Si bien esta observación es doctrinal, y no legal.

65 Aunque se hallan previstas para las manipulaciones operativas, podrían servir de alguna guía para comprobar las informativas, como advierte GómezJara (en El delito de manipulación de mercado, cit., pp. 86-87). Máxime, si se relativiza, precisamente a causa de la inclusión de la modalidad de transmisión de señales en los apdos. $2^{\circ}$ y $3^{\circ} \mathrm{del}$ art. 284.1 C.P., la ubicación de unas y otras clases de manipulación. 
dad penal en comisión por omisión cuando el cumplimiento de los deberes de información por parte del autor habría evitado la alteración o preservación del precio de cotización del instrumento financiero y se dan los restantes requisitos que establece el artículo 11 del Código Penal ${ }^{66}$.

A pesar de su confusa estructura, la conducta típica permite distinguir entre modos y medios (o instrumentos) de ejecución. Los primeros, suponen formas de llevar a cabo la conducta $\mathrm{y}$, como he señalado, en el precepto se corresponden, a mi juicio, con las modalidades típicas de difundir noticias o rumores o transmitir señales falsas o engañosas. Los segundos, pueden reconocerse en las siguientes referencias del artículo: "a través de un medio de comunicación, por medio de internet o mediante el uso de tecnologías de la información y la comunicación, o por cualquier otro medio, difundieren noticias o rumores o transmitieren señales falsas o engañosas [...]". Como se ve, es evidente la amplitud de la fórmula utilizada para los instrumentos comisivos, que permitiría acoger incluso -dentro de los límites de la imputación objetiva- casos de distorsión y manipulación de la información sobre personas o empresas a través de las redes sociales. Y dicha fórmula alcanza claramente, por razones sintácticas, a ambas modalidades de la conducta, difundir o transmitir.

La letra del Código ha quedado demasiado circunscrita con respecto al contenido de los objetos de las conductas. La naturaleza de la información que se ofrece por los modos típicos se limita a la relativa a "datos económicos". También aquí se trata de una exigencia que permanece de la regulación penal precedente, pero que no consta en la Directiva de abuso de mercado.

66 Véase, con importantes matices con respecto al objeto de protección del delito de manipulación de mercado y el sentido de los deberes de información impuestos por la correspondiente normativa, Estrada i Cuadras: "Presente y futuro del delito de alteración de precios (art. $284 \mathrm{Cp}$ )", cit., pp. 25-26. Admitiendo también la posibilidad de la comisión por omisión véase GómezJara Díez: El delito de manipulación de mercado, cit., pp. 82-83. Sobre los deberes de información impuestos por la legislación del mercado de valores, véanse los arts. 209 y 282.3, 4, 7 de la Ley del Mercado de Valores. 
Esto podría resultar problemático en la práctica, porque, en principio, reduce el campo semántico de la "información" a la que se refiere amplísimamente la norma europea [art. 5.2, c): "difundir información"]. En efecto, la expresión legal "datos económicos" es mucho más concreta y conduciría a considerar excluida, por un lado, información no económica y, por otro, a excluir también aquella que, siendo económica, no posea una referencia objetiva ("dato"). De este modo, llevaría a entender que no puede tratarse de datos de naturaleza no económica, como la enfermedad de un empleado altamente cualificado, o de un manager, decisivos para la compañía, o su procesamiento penal, la toxicidad de un producto o, incluso, el fracaso de una importante investigación para desarrollar una nueva línea de producto. Sin embargo, algunas razones pugnan para interpretar más abiertamente la expresión legal. Por un lado, el que la difusión de las noticias o rumores, o la transmisión de las señales falsas o engañosas, deba ser -conforme al artículo- "sobre personas o empresas". Por otro lado, la restricción que significa con respecto a la Directiva, que habla solamente de "información". Y, además, por otro, porque un dato que por sí no posea naturaleza económica puede adquirirla por el contexto en el que se utiliza. Este es el caso de los ejemplos anteriores. Pero es cierto que esta interpretación abriría en exceso la referencia legal si no se exige que la información objetiva posea un carácter absolutamente fundamental a efectos de tomar la decisión de realizar la inversión o desinversión ${ }^{67}$.

Otro aspecto típico que afecta al objeto de la conducta es el carácter "total o parcialmente falso" de los datos económicos (ya con origen en la reforma de 2010). En particular, la alusión a datos "parcialmente falsos" plantea la necesidad de distinguir

67 Véase, de forma similar, Estrada i Cuadras: "Presente y futuro del delito de alteración de precios (art. 284 Cp)", cit., p. 19; también, Gómez-Jara Díez, interpretando que basta que la información posea la virtualidad necesaria para producir un alza o una baja de los precios, incluyendo las valoraciones o los pronósticos que posean una referencia objetiva (en El delito de manipulación de mercado, cit., pp. 78-81). Y Feijoo Sánchez: "Los delitos de manipulación del precio de cotización de un instrumento financiero del art. 284 CP tras la LO 1/2019”, cit., p. 16. 
entre lo inexacto y lo falso, y es razonable que en la praxis se interprete valorando la idoneidad objetiva del dato para provocar error en un círculo relevante de inversores ${ }^{68}$. Con todo, se trata de un campo apto para que pueda tener lugar un error acerca de la falsedad de la información, que constituirá un error de tipo que determinará aquí la impunidad del hecho ante la impunidad de la forma imprudente de comisión del delito.

\subsection{Especial referencia a la exigencia de beneficio $y$ otras circunstancias de la tipicidad}

El delito consumado precisa que el hecho desemboque en la obtención de un beneficio. En otro caso, solo será punible como tentativa. Antes de la reforma de 2019 se requería que alcanzara un importe superior a $300.000 €$, o que alternativamente se causara un perjuicio de idéntica cantidad, pero ahora ni la suma concreta del beneficio, ni la causación de un perjuicio juegan un papel decisivo sin la consecución de algún beneficio. Para entender esto último es necesario observar que el artículo 284.1.2 $2^{\circ}$ condiciona el castigo, además de al beneficio obtenido ("cuando obtuvieran, para sí o para tercero, un beneficio"), a que se dé alguna de las siguientes circunstancias ${ }^{69}$ alternativas: a) que dicho beneficio fuera superior a doscientos cincuenta mil euros o se causara un perjuicio de idéntica cantidad; b) que el importe de los fondos empleados fuera superior a dos millones de euros; o c) que se causara un grave impacto en la integridad del mercado ${ }^{70}$.

68 Coincido con Gómez-Jara Díez (en op. ult. cit., pp. 81-82).

69 Consideradas como "requisitos típicos" por Gómez-Jara Díez/Tejada Plana (en "La reforma del delito de manipulación de mercado en el Código Penal español”, cit., p. 10). También en opinión de Feijoo Sánchez (en op. ult. cit., p. 13), se trata de elementos típicos que caracterizan la gravedad del injusto específicamente penal frente al injusto administrativo y no de meras condiciones objetivas de punibilidad. A mi juicio, esta naturaleza es clara con respecto a las circunstancias b) y c), pero es probable que en la práctica se avive el debate sobre la naturaleza de condición objetiva de punibilidad con respecto a la circunstancia a).

70 Algunos autores se muestran, con razón, muy críticos con el papel típico del que se ha dotado a la "integridad del mercado", porque debido su defecto de taxatividad ocasionará problemas en la práctica. Así, Gómez Pavón: “El 
De modo que es necesario que el ofrecimiento de datos económicos falsos de lugar a la obtención de un beneficio para el agente o para un tercero ${ }^{71}$. Pero ello no basta, porque además deberá concurrir alguna de las circunstancias señaladas. En consecuencia, el beneficio podrá ser de cualquier entidad si el importe de los fondos empleados fuera superior a dos millones de euros [circunstancia b)] o si se causara un grave impacto en la integridad del mercado [circunstancia c)]. En otro caso (es decir, si no se diera ninguna de las referidas circunstancias), el beneficio deberá ser superior a doscientos cincuenta mil euros o, alternativamente, entrará en juego el perjuicio, que habrá de ser de idéntica cantidad (la reforma ha reducido el umbral del beneficio o perjuicio desde los 300.000 a $250.000 €$, aunque como se ve ahora esta cantidad no desempeña el papel decisivo que antes poseía para incurrir en responsabilidad por el delito) [circunstancia a)]. Esto se traduce en que, por ejemplo, pueden castigarse como delitos de manipulación hechos en los que el montante de los fondos empleados sea particularmente notorio o siempre que se cause un grave impacto a la integridad del mercado, aunque el beneficio obtenido sea mínimo. Fuera de estos casos, el beneficio deberá superar los $250.000 € \mathrm{o}$, habiendo un beneficio de menor importe, el perjuicio deberá exceder de los $250.000 €$. En estos últimos supuestos, si el beneficio o el perjuicio no alcanzaran esa suma, siendo que la cuantía de los fondos empleados tampoco superara los dos millones de euros

delito de alteración de precios", en La Ley Penal: Revista de Derecho penal, procesal y penitenciario, cit., p. 8. También, Gómez-Jara Díez/Tejada Plana: "La reforma del delito de manipulación de mercado en el Código Penal español", cit., p. 9. Además, se ha señalado que "no hay una doctrina consolidada (ni en España ni fuera de nuestras fronteras) sobre el significado del objetivo legal de la «integridad del mercado» al que se dirigen las normas reguladoras del abuso de mercado" (Martínez Flórez: "Los fundamentos de la prohibición del abuso de mercado", cit.).

71 Cfr., sin embargo, Gómez Pavón, afirmando que "la consumación se producirá cuando se difunda la noticia o rumor falso, sin que sea preciso que tenga lugar el perjuicio o beneficio, revistiendo la forma de delito de mera actividad" (en "El delito de alteración de precios", cit., p. 9). 
y no se hubiese causado un grave impacto en la integridad del mercado, la infracción quedaría en el ámbito del Derecho administrativo sancionador ${ }^{72}$. Pero todas las circunstancias apuntan, con diferentes parámetros, a la entidad que debe poseer la manipulación $^{73}$.

Así, pues, el beneficio, constituye un elemento imprescindible para el delito, pero no suficiente. La nueva regulación ya no se presta a plantear en los mismos términos la polémica que bajo la regulación anterior ocupó a la doctrina y la jurisprudencia con respecto a su naturaleza jurídica del beneficio económico o del perjuicio como resultado típico o condición objetiva de punibilidad ${ }^{74}$. La conclusión era fundamental porque de ello dependía, entre otros aspectos, el que el resultado fuera imputado objetiva y subjetivamente al autor. Y el debate fue abierto y alimentado, fundamentalmente ${ }^{75}$, por la exigencia legal de que el beneficio o el perjuicio fuera superior a $\operatorname{los} 300.000 €$, debido, por una parte, a las dificultades para distinguir la cantidad imputable a la conducta del autor del beneficio o del perjuicio y, por otra, y también en relación con ello, para que el dolo del autor alcance dicho importe ${ }^{76}$. Aunque la doctrina se encontraba dividida, es sintomático que la conclusión de la jurisprudencia fuese que se trataba de una condición objetiva de punibilidad.

72 Véanse los arts. 282.15 (infracción muy grave) y 295.13 (infracción grave), por incumplimiento de la prohibición de manipulación o intento de manipulación del mercado establecida en el art. 15 Reglamento (UE) 596/2014 sobre abuso de mercado.

73 Como afirma Feijoo Sánchez, la manipulación debe objetivarse así con una determinada intensidad (en "Los delitos de manipulación del precio de cotización de un instrumento financiero del art. 284 CP tras la LO 1/2019”, cit., p. 12).

74 Así, TS, por ejemplo, en el “caso Parquesol”, STS 491/2015.

75 Además de por otras razones que siguen en el texto.

76 Sobre el debate, véase Nieto Martín, A.: "El insider trading despierta de su largo sueño. A propósito de la Sentencia del Tribunal Supremo de 23 de julio de 2015", en el blog de Jesús Alfaro, Universidad Autónoma de Madrid, “Almacén de Derecho", 4 de enero 2016 (https://almacendederecho. org/insider-trading-o-trafico-con-informacion-privilegiada/). 
Después de la reforma de 2019, la nueva regulación del delito ofrece mejores anclajes para concluir que el beneficio que aparece como condictio sine qua non constituye el resultado típico del delito. Precisamente, por su desvinculación de un determinado importe, pero también porque el legislador asume expresamente el castigo de la tentativa que como vimos impone la Directiva (algo incompatible con la naturaleza de este elemento como condición objetiva de punibilidad ${ }^{77}$. Sigue presentándose, es cierto, el inconveniente de que el beneficio solamente se puede relacionar indirectamente con el injusto de este delito. Pero esto no significa que sea un elemento completamente ajeno al mismo y, por lo tanto, indiferente desde el punto de vista del daño a la integridad del mercado. Feijoo ha observado que el hecho de que el papel del beneficio no solamente opere en este punto, sino que influya también como módulo de la penalidad (en la pena de multa proporcional, art. 284.1, párrafo primero) y se tenga en cuenta como subtipo agravado (notoria importancia, art. 284.2.2 $2^{\mathrm{a}}$ ), pone de manifiesto su vinculación con el injusto ${ }^{78}$. $\mathrm{Al}$ respecto, además, se halla una razón de peso de tal vinculación en que la propia Directiva de abuso de mercado señala que la manipulación de mercado se debe considerar grave en casos en que sea elevado el beneficio derivado real o potencial [considerando (12)]. No obstante, es posible que la referencia al beneficio, en relación con la pena, fuera de índole político-criminal, y no sustantiva, puesto que es indudable que una pena determinada conforme a su importe, o una agravación determinada por su notoria importancia, contiene un mensaje de considerable eficacia disuasoria.

Ciertamente, con el nuevo texto del artículo 284.1.2 $2^{\circ}$, la discusión acerca de la naturaleza del beneficio puede reproducirse de nuevo en la práctica con respecto a la primera circunstancia adicional ("que dicho beneficio fuera superior a doscientos

77 Como subraya Feijoo Sánchez en "Los delitos de manipulación del precio de cotización de un instrumento financiero del art. 284 CP tras la LO 1/2019", cit., p. 14.

78 Op. cit., p. 15. 
cincuenta mil euros o se causara un perjuicio de idéntica cantidad"). Sin embargo, el problema podrá soslayarse cuando exista alguna alternativa por las vías que ofrecen las demás circunstancias (es decir, cuando el importe de los fondos empleados fuera superior a dos millones de euros o se causara un grave impacto en la integridad del mercado), cuya vinculación con el injusto del hecho [que también resulta del considerando (12) de la Directiva, al hacer depender el carácter "grave" de la manipulación de mercado de circunstancias que constituyen los supuestos agravados del Código ${ }^{79}$ ] es clara.

En todo caso, volviendo al beneficio que opera como condición básica para la responsabilidad por estos hechos, se planteará el problema, puesto también de manifiesto a propósito de la regulación anterior, primero, para establecer el momento en que se ha de determinar (¿el instante en que ha subido el precio; cuando se ha realizado la desinversión o la inversión?) $\mathrm{y}$, segundo, para conocer qué parte del beneficio, en su caso, es imputable a su conducta para probar que procede, precisamente, de la interferencia del autor en la "normalidad" del mercado. Aunque se ha señalado que el registro de las operaciones y de los operadores en los modernos mercados permite contar con una información que puede ser concluyente en muchos casos para comprobar esta conexión ${ }^{80}$, la dificultad será mayor cuanto menor sea el beneficio constatado.

Por último, no especifica el Código Penal que el beneficio (básico) deba ser económico. Es más, en la infracción concordante prevista en la Directiva de abuso de mercado, se alude a

79 Aunque debe señalarse que la Directiva no establece cantidades, sino que alude "elevado" impacto en la integridad del mercado o el beneficio derivado real o potencial o las pérdidas evitadas, a la "importancia" del daño causado al mercado o al "importe" de los fondos utilizados inicialmente (por cierto, entre otros criterios que, sin embargo, no han llegado al Código Penal español, como el nivel de la alteración del valor del instrumento financiero o del contrato de contado sobre materias primas).

80 Así, Estrada i Cuadras: "Presente y futuro del delito de alteración de precios (art. 284 Cp)", cit., p. 23. 
"ventaja o beneficio" [art. 5.2, c)]. No obstante, parece que debe entenderse en su sentido económico, teniendo en cuenta cómo prosigue el artículo al enunciar las condiciones subsiguientes, diciendo "a) que dicho beneficio...".

\subsection{Otros aspectos de la tipicidad}

A la vista de la configuración de la conducta, desde el punto de vista del injusto, cabe concluir que el delito del artículo 284.1.2 $2^{\circ}$ presenta los rasgos de una figura de peligro abstracto o de lesión, según la modalidad de la que se trate, teniendo en cuenta el efecto del comportamiento sobre el bien jurídico considerado la "integridad del mercado" [peligro abstracto en caso de ofrecer a sabiendas datos económicos total o parcialmente falsos obteniendo un beneficio o causando un perjuicio en los términos de la circunstancia a), o cuando el importe de los fondos fuera superior a dos millones de euros; lesión, cuando la conducta causara un grave impacto en la integridad del mercado].

En cuanto al sujeto que realiza la conducta, la nueva redacción resulta extraordinariamente confusa, porque mezcla aspectos que se refieren a la delimitación del sujeto activo y el título de intervención personal (al decir "por sí, de manera directa o indirecta..."), con aspectos que conciernen a los medios comisivos (la mención que sigue inmediatamente como alternativa, sin separación gramatical, diciendo: “...o a través de un medio de comunicación...”). La nueva expresión legal parece que, partiendo de la del apartado correspondiente a este ("por sí o a través de un medio de comunicación", art. $284.2^{\circ}$ antes de la reforma de 2019), ha tratado de ampliar los modos entonces previstos de intervención del autor del hecho, sin embargo, la formulación final resulta no solo confusa, sino también innecesaria. En lo que se refiere a los medios, por su abierta forma de cierre: “...o por cualquier otro medio". Y, por su parte, la fórmula "por sí, de manera directa o indirecta...", no podría interpretarse como una cláusula legal de autoría extensiva (es decir, que permita considerar como conductas de autor cualesquiera contribuciones 
al hecho, directas o indirectas), sino como un modo de concebir autorías directas y otras indirectas (como la inducción o la autoría mediata). Ello es así porque el precepto exige que el sujeto lleve a cabo el hecho típico, ya de una forma directa, ya indirecta (pero no parcial o fragmentaria). En todo caso, ninguno de estos incisos aporta nada que no sea mayor confusión al régimen de las reglas generales de la autoría y la participación. Por lo demás, sigue siendo un sujeto que no requiere especialidad alguna.

Por último, el aspecto subjetivo del delito no ha experimentado cambios, salvo por lo que resulta de la incorporación de nuevos objetos de los precios, pues la finalidad típica de "alterar o preservar el precio" no solamente alcanza a la cotización de un instrumento financiero (como antes), sino que se extiende también a "contratos de contado sobre materias primas relacionados" (relacionados con instrumentos financieros). A esta finalidad se añade como objetivo alternativo el de "manipular el cálculo de un índice de referencia", por la misma razón.

Ante la regulación anterior, con una expresión idéntica ("con el fin de alterar o preservar el precio", art. $284.2^{\circ}$ ), el criterio doctrinal dominante fue que en la parte subjetiva el tipo estaba marcado por la presencia de un elemento subjetivo configurado por la finalidad manipuladora de los precios, limitador del alcance típico e incompatible con el dolo eventual ${ }^{81}$. Y con la nueva regulación debe llegarse a la misma conclusión: el tipo mantiene su configuración de delito de resultado cortado con la exigencia de que la conducta se realice "con el fin de alterar o preservar el precio de cotización de un instrumento financiero o un contrato de contado sobre materias primas relacionado o de

81 Véase, con referencias, Paredes Castañón: "Problemas de tipicidad en las conductas de manipulación de precios de los mercados de valores", cit., p. 40. También, Galán Muñoz, A.: "Mentiras y medias verdades en los mercados financieros. Una aproximación crítica a la posible incriminación de las «erróneas» calificaciones realizadas por las agencias de calificación crediticia", en Tamarit Sumalla, J.Ma./Morales Prats, F./García Albero, R.: Represión Penal y Estado de Derecho. Homenaje al Profesor Gonzalo Quintero Olivares, Ed. Aranzadi, Cizur Menor, 2018, p. 663. 
manipular el cálculo de un índice de referencia”, que sirve para canalizar la orientación del dolo mediante un elemento subjetivo adicional. Pero el que tenga que concurrir tal finalidad especial de incidir sobre el mercado no impide (en contra de lo que ha sostenido la jurisprudencia ${ }^{82}$ ) que el propósito del autor sea el ánimo de lucro, directo (obtener un beneficio), como indirecto

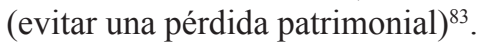

No obstante, la compleja estructura de la nueva conducta permite concebir diferentes exigencias desde el punto de vista subjetivo, proyectadas sobre la conducta (ofrecer a sabiendas datos económicos total o parcialmente falsos) y las circunstancias de las letras a), b) y c). Por ello, sería compatible la actuación con dolo eventual con respecto a estas circunstancias ${ }^{84}$.

Con todo, la exigencia de la Directiva se ve excedida por la, más concreta, del Código Penal, pues aquella requiere solamente que las infracciones penales se hayan cometido intencionalmente [art. 5.1, de acuerdo con el considerando (10)], a diferencia de las infracciones del Reglamento 596/2014 [véase el considerando (23)].

\section{Novedades con respecto al delito de manipulación opera- tiva (art. 284.1.3 $\left.{ }^{\circ}\right)$}

El artículo $284.1 .3^{\circ}$ recoge la realización de una serie de operaciones engañosas o abusivas dirigidas a alterar la formación de los precios de instrumentos financieros, contratos de contado sobre materias primas relacionados con ellos o índices de referencia.

82 Véase, muy crítico, Paredes Castañón: op. cit., p. 6.

83 Como aclaraba García-Pablos a propósito de la cuestión con respecto al delito de maquinaciones para alterar los precios [en "Sobre la figura del delito para alterar los precios (naturales) de las cosas", cit., p. 236]. También, y con más referencias, Paredes Castañón: op. cit., p. 42.

84 Así, Feijoo Sánchez: "Los delitos de manipulación del precio de cotización de un instrumento financiero del art. 284 CP tras la LO 1/2019", cit., p. 15-16. 
Castiga a quienes "realizaren transacciones, transmitieren señales falsas o engañosas, o dieren órdenes de operación susceptibles de proporcionar indicios falsos o engañosos sobre la oferta, la demanda o el precio de un instrumento financiero, un contrato de contado sobre materias primas relacionado o índices de referencia, o se aseguraren, utilizando la misma información, por sí o en concierto con otros, una posición dominante en el mercado de dichos instrumentos o contratos con la finalidad de fijar sus precios en niveles anormales o artificiales, siempre que concurra alguna de las siguientes circunstancias: a) que como consecuencia de su conducta obtuvieran, para sí o para tercero, un beneficio superior a doscientos cincuenta mil euros o causara un perjuicio de idéntica cantidad; b) que el importe de los fondos empleados fuera superior a dos millones de euros; c) que se causara un grave impacto en la integridad del mercado."

Así, pues, el precepto añade a las modalidades ya vistas otras que, en sus aspectos fundamentales, consisten en actuar en los mercados bien dando señales falsas o engañosas sobre aspectos que condicionan la formación de los precios (oferta, demanda), o los precios mismos, de un instrumento financiero, un contrato de contado sobre materias primas relacionado o índices de referencia, bien asegurándose una posición dominante para fijar tales precios en niveles artificiales.

Su castigo se hace aquí depender de alguna de las condiciones alternativas que, de forma similar al apartado anterior ${ }^{85}$, consisten en la obtención de un determinado beneficio (o causación de un perjuicio determinado), un cierto importe de la operación o la causación de un grave impacto en el mercado. Pero con una diferencia significativa en comparación con las manipulaciones informativas (art. 284.1.2 ${ }^{\circ}$ ): aquí puede haber responsabilidad penal sin que haya habido beneficio alguno [en caso de que se den las circunstancias b) o c)].

85 Aunque no igual, sin que se puedan adivinar los motivos. Por ejemplo, obsérvese la diferente formulación de los correspondientes apartados "a)". 
La nueva regulación sigue siendo, no obstante, tan complicada, o más, que la precedente. El delito se articula, a partir de un sujeto común, en cuatro modalidades alternativas: las tres primeras, caracterizadas por su prevalente contenido falsario, y la cuarta, por el abuso de posición dominante en el mercado. Tras la reforma de 2019, como ya avancé, ha desaparecido del texto la que consistía en utilizar "información privilegiada", en coherencia con la Directiva 2014/57, que no dota de relevancia al carácter privilegiado de la información a efectos de las manipulaciones de los precios de mercado.

Las primeras formas típicas (realizar transacciones, transmitir señales falsas o engañosas y dar órdenes de operación) tienen en común que las actuaciones o el objeto sobre los que recaen las hace susceptibles de proporcionar indicios falsos o engañosos sobre la oferta, la demanda o el precio, tanto de instrumentos financieros, como de contratos de contado sobre materias primas relacionados con ellos e incluso sobre índices de referencia. La última de las conductas (asegurar una posición dominante en el mercado de dichos instrumentos o contratos), aunque se sustancia en la utilización de la misma clase de informaciones (por el propio sujeto o en concierto con otros), centra su desvalor en el aseguramiento de una posición de dominio en el mercado de dichos instrumentos o contratos. Con estas figuras se trata de poner límites a las manipulaciones realizadas mediante fórmulas como las operaciones de autocartera, las ventas en corto al descubierto y otras formas de negociación capaces de provocar bruscas fluctuaciones en el mercado con fines especulativos, como cuando se utiliza la negociación de alta frecuencia o las operaciones ultrarrápidas o flash $^{86}$.

86 Las operaciones de autocartera consisten en la negociación de las acciones de la propia entidad titular para alterar la cotización al alza o a la baja. Aunque estas operaciones pueden servir a necesidades de estabilización de la cotización, pueden también prestarse a abusos (y, en todo caso, como ha afirmado la CNMV, "toda operativa de autocartera entraña un riesgo para la integridad del mercado", véase el "Comunicado de la CNMV dejando sin efecto los criterios sobre operativa discrecional de autocartera de 2013", 
El aseguramiento de una posición de dominio supone alcanzar en el mercado la capacidad suficiente para obstaculizar o impedir la competencia; en definitiva, conseguir la posibilidad de hacer valer sus preferencias en el mercado, con independencia de las actuaciones de otros operadores. Pero se trata de un supuesto típico muy difícil de delimitar con respecto a las conductas permitidas.

Por razones análogas a las expuestas con ocasión del análisis de las figuras del artículo 284.1.2 $2^{\circ}$, en este apartado $3^{\circ}$

de 13 de enero de 2020). Las ventas en corto (short selling) consisten en operaciones realizadas con valores adquiridos en préstamo con el fin de ser devueltos al propietario en la fecha de liquidación. La ventaja que obtiene el prestamista procede del interés que cobra por el préstamo de los valores. Por su parte, el prestatario puede obtener un beneficio por la diferencia del precio de la venta de los valores y de la compra posterior para su reintegro al titular. La venta en corto será "al descubierto" (naked short selling) si la venta del título se produce sin la posesión del activo. Aunque las ventas en corto poseen la importante ventaja de que facilitan la liquidez y amplían las posibilidades de participación de los ciudadanos en el mercado de valores, pueden servir de instrumento para el abuso de mercado si se utilizan para atacar a unos títulos o sectores concretos, con perjuicio para las sociedades cotizadas. Pueden también prestarse a abusos de préstamos en cadena (descubiertos), con riesgo de no reposición y generar riesgos de desestabilización de las cotizaciones y el sistema financiero. Sobre ello véase Hurtado "Las ventas a corto y los hedge funds. Implicaciones en la estabilidad financiera", Fundación de Estudios Financieros (en https://www.fef.es/publicac iones/.../446 9b410d7848d209532cf095011e13f4ba.html). La negociación de alta frecuencia (o black box trading) se basa en el uso de ordenadores de alta velocidad controlados por algoritmos destinados a analizar datos, identificar oportunidades de inversión y gestionar el flujo de las órdenes hacia los mercados. Con este sistema es posible transmitir a una bolsa miles de órdenes por minuto y con la misma velocidad pueden cancelarse y sustituirse por otras órdenes nuevas (según estimaciones, el 90\% de las órdenes transmitidas por este sistema se cancelan). Véase sobre ello Dodd, R.: “Transacciones", en Finanzas y Desarrollo, marzo 2010. Véase una amplia relación de las manipulaciones más comunes, como wash trades, improper matched orders, etc., en Gómez-Jara Díez: El delito de manipulación de mercado, cit., pp. 97-102; véase también Feijoo Sánchez, B.: Orden socioeconómico y delito. Cuestiones actuales de los delitos económicos, Ed. B de f, Montevideo-Buenos Aires, 2016, p. 69. De nuevo, a los efectos de saber cuándo se han transmitido señales falsas o engañosas, pueden verse los indicadores que ofrece el Anexo I del Reglamento (UE) 596/2014. 
las dos conductas típicas pueden ser aquí identificadas por las referencias al suministro de indicios falsos o engañosos sobre la oferta, la demanda o el precio de un instrumento financiero, un contrato de contado sobre materias primas relacionado o índices de referencia, y al aseguramiento de una posición dominante en el mercado. A mi modo de ver, la "realización de transacciones", la "transmisión de señales falsas o engañosas" o la "dación de órdenes de operación" constituyen modos diversos de llevar a cabo la primera conducta. Con respecto a la conducta que consiste en asegurarse una posición dominante, la alusión a que se lleve a cabo "utilizando la misma información" ha permanecido como un clarísimo residuo de la regulación anterior que difícilmente puede tener el sentido de un medio o modo comisivo dada su absoluta incompatibilidad gramatical en el contexto del actual precepto ${ }^{87}$.

El castigo de tales conductas se hace depender de las mismas circunstancias contempladas en el artículo anterior [a) beneficio superior a doscientos cincuenta mil euros o perjuicio de idéntica cantidad; b) importe de los fondos empleados superior a dos millones de euros; y c) grave impacto en la integridad del mercado]. Su interpretación se remite, por ello, a lo ya señalado con ocasión del artículo 284.1.2 ${ }^{\circ}$.

En cuanto al aspecto subjetivo, se trata de un delito doloso y se especifica la finalidad de fijar los precios de los valores o instrumentos financieros en niveles anormales o artificiales. Esta carga subjetiva, no obstante, no dista tanto del contenido que corresponde al dolo, pero en cualquier caso posee la virtualidad de dificultar la posibilidad de apreciar el dolo eventual (aunque no con respecto de las circunstancias aludidas más arriba). Sigue siendo problemático, desde el punto de vista gramatical, si esta

87 Sosteniendo, sin embargo, que no puede ignorarse la exigencia legal, Feijoo Sánchez considera que debe interpretarse que alude a "cualquier información relevante para la oferta, la demanda o el precio de un instrumento financiero o de un contrato de contado sobre materias primas relacionado" (en "Los delitos de manipulación del precio de cotización de un instrumento financiero", cit., p. 17). 
cláusula finalística afecta solamente a la última de las formas típicas o a todas ellas, a consecuencia de la puntuación de esta parte del precepto. Aun así, parece que alcanzaría a todas las conductas del artículo 284.1.3

Por último, como se ha advertido ya, la reforma no ha incorporado la cláusula de exoneración de la responsabilidad que contempla la Directiva 2014/57 diciendo: "a menos que las razones por las que la persona que hubiese efectuado la operación o dado las órdenes de negociación sean legítimas y que esas operaciones u órdenes se ajusten a las prácticas de mercado aceptadas en el centro de negociación de que se trate" (art. 5.2, ii, párrafo segundo). Sin embargo, ello no significa que los jueces españoles no puedan considerar estos criterios, aplicando la teoría de la imputación objetiva (riesgo permitido) y las causas de justificación (véase, con respecto a las prácticas de mercado aceptadas, el art. 13 del Reglamento 596/2014 ${ }^{88}$ ).

\section{Comparación de las novedades con las obligaciones de la Directiva de abuso de mercado}

Hemos visto en los apartados anteriores las modificaciones introducidas por la ley de reforma de 2019 en el artículo 284. Es hora, a continuación, de revisar la correspondencia de las infracciones de la Directiva con el resultado de la modificación del Código Penal. No es esta, sin embargo, una tarea sencilla, porque a la dificultad para presentar directamente las conductas punibles contempladas en la Norma europea se añade la de unas

88 En situaciones específicas, y por razones económicas claras, se permitirán exenciones, no aplicándose determinadas prohibiciones. En virtud de las llamadas "prácticas aceptadas de mercado" se permite no penalizar actuaciones que podrían dar lugar a manipulación. Sin embargo, para evitar prácticas dispares entre los Estados miembros, se modifica el procedimiento para su aprobación. El Reglamento Delegado (UE) No 2016/908 establece los estándares técnicos para la aprobación de este tipo de prácticas. Sobre los riesgos financieros permitidos véase Feijoo Sánchez: Orden socioeconómico y delito, cit., pp. 73-80. 
formulaciones típicas del Código Penal alambicadas y poco rigurosas.

Antes de proceder a este intento, debo hacer las siguientes aclaraciones sobre el modo de exposición de los delitos en la siguiente figura, que responde al modo de entender que he expuesto en páginas anteriores de su estructura y su configuración en relación con el injusto. En primer lugar, la Directiva, en su artículo 5.2, describe las "actividades" que constituyen manipulación de mercado enunciando, primero, las acciones (por ejemplo, "ejecutar una operación" o "dar una orden de negociación”) y, segundo, los resultados (por ejemplo, "que... transmita señales falsas o engañosos" o "que... afecte al precio"). Estos segundos constituyen los núcleos del injusto, pues describen la incidencia de la conducta en el bien jurídico protegido, mientras que aquellas aluden a los medios o modos típicos de ejecución. Por esta razón, he optado por presentar las conductas de la Directiva partiendo de los resultados, y no de las acciones. En segundo lugar, las modalidades delictivas del artículo $284.1 \mathrm{del}$ Código Penal, de un modo análogo en cuanto a su estructura, se hallan construidas en torno a los tres núcleos de injusto siguientes: alterar precios (art. 284.1.1 ${ }^{\circ}$ ), ofrecer datos económicos total o parcialmente falsos (art. 284.1.2 $)$ y proporcionar indicios falsos o engañosos... o asegurarse una posición dominante en el mercado (art. $284 \cdot 1 \cdot 3^{\circ}$ ). Junto a estos, se consigna toda una serie de medios o modos de ejecución ("difundieren noticias falsas", "transmitieren señales falsas o engañosas", "realizaren transacciones", "dieren órdenes de negociación”, etc.). Pues bien, en la figura siguiente se presenta la posible correspondencia de unas y otras modalidades de infracción penal. 
Figura 2. Comparación de los delitos de manipulación de mercado de la Directiva 2014/57 y del Código Penal tras la L.O. 1/2019, de modificación del Código Penal

\begin{tabular}{|c|c|c|}
\hline \multicolumn{2}{|c|}{ Directiva 2014/57/UE [art. 5.2, a), b), c) y d)] } & \multirow[b]{2}{*}{$\begin{array}{l}\left.\text { Código penal (art. 284.1, } \mathbf{1}^{\circ}, \mathbf{2}^{\circ} \text { y } \mathbf{3}^{\circ}\right) \\
\begin{array}{l}\text { ofrecer datos económicos } \\
\text { falsos }\left(2^{\circ}\right) \\
\cdot \text { proporcionar indicios } \\
\text { susceptibles de confundir o } \\
\text { engañar }\left(3^{\circ}\right)\end{array}\end{array}$} \\
\hline $\begin{array}{l}\text { transmitir señales } \\
\text { falsas/engañosas } \\
{[\mathrm{a}), \text { i) y c)] }}\end{array}$ & $\begin{array}{l}\text { ejecutando una operación }[a), \text { i)] } \\
\cdot \text { dando una orden de negociación } \\
[\mathrm{a}), \mathrm{i})] \\
\cdot \text { difundiendo información }[\mathrm{c})] \\
\cdot \text { mediante cualquier otra conducta } \\
[\mathrm{a}), \mathrm{i})]\end{array}$ & \\
\hline \multirow[t]{2}{*}{$\begin{array}{l}\text { fijar precios en } \\
\text { un nivel anormal o } \\
\text { artificial / afectar } \\
\text { a precios [a), ii), } \\
\text { b) y c)] }\end{array}$} & $\begin{array}{l}\text { - ejecutando una operación [a), ii) } \\
\text { y b)] } \\
\cdot \text { dando una orden de negociación } \\
{[»]} \\
\cdot \text { difundiendo información }[c)] \\
\text { - mediante cualquier otra conducta } \\
\text { [a), ii) y b): mediante mecanismos } \\
\text { ficticios o cualquier forma de engaño } \\
\text { o artificio] }\end{array}$ & $\begin{array}{l}\text { alterar precios }\left(1^{\circ}\right) \\
\text { ofrecer datos económicos } \\
\text { falsos }\left(2^{\circ}\right)\end{array}$ \\
\hline & & $\begin{array}{l}\cdot \text { asegurarse una posición } \\
\text { dominante }\left(3^{\circ}\right)\end{array}$ \\
\hline $\begin{array}{l}\text { manipular } \\
\text { el cálculo de } \\
\text { un índice de } \\
\text { referencia }[\mathrm{d})]\end{array}$ & $\begin{array}{l}\text { - transmitiendo información falsa/ } \\
\text { engañosa [d)] } \\
\cdot \text { suministrando datos falsos/ } \\
\text { engañosos [d)] } \\
\cdot \text { mediante cualquier otra conducta } \\
{[\text { d)] }}\end{array}$ & $\begin{array}{l}\text { - alterar precios }\left(1^{\circ}\right) \\
\text { - ofrecer datos económicos } \\
\text { falsos }\left(2^{\circ}\right) \\
\cdot \text { proporcionar indicios } \\
\text { susceptibles de confundir o } \\
\text { engañar }\left(3^{\circ}\right)\end{array}$ \\
\hline
\end{tabular}

La primera observación que resulta inmediatamente de la comparación es que los comportamientos guardan entre sí una correspondencia muy forzada y que, en consecuencia, la relación es, en efecto, asimétrica ${ }^{89}$.

Debe decir: La transmisión de señales falsas o engañosas difundiendo información, recogida en la Directiva en el artículo $5.2, \mathrm{c})$, puede verse reflejada en la conducta del artículo $284.1 .2^{\circ}$ del Código penal descrita como ofrecer datos económicos total o parcialmente falsos (bien difundiendo noticias o rumores, bien transmitiendo señales falsas o engañosas). La transmisión de señales falsas o engañosas ejecutando una operación o dando una orden de negociación, contemplada el artículo 5.2, a), i) de la Directiva, puede verse reflejada en la conducta del artículo $284.1 .3^{\circ} \mathrm{del}$

89 Gómez-Jara Díez/Tejada Plana: "La reforma del delito de manipulación de mercado en el Código Penal español”, cit., p. 1. 
Código penal descrita como proporcionar indicios susceptibles de confundir o engañar. Sin embargo, la transmisión de señales falsas o engañosas mediante cualquier otra conducta, del artículo 5.2, a), i) de la Directiva, no se ve recogida en el artículo 284.1 del Código penal, pues la alusión abierta en este artículo a los medios comisivos ("o por cualquier otro medio"), no posee el mismo significado.

La fijación de precios en un nivel anormal o artificial o la afectación a los precios, que en la Directiva aparece en el artículo 5.2. a), ii), b) y c), puede hallar su equivalencia en las figuras de alteración de precios (art. 284.1.1 ${ }^{\circ}$ C.P.) y de ofrecimiento de datos económicos total o parcialmente falsos (art. 284.1.2 $2^{\circ}$ ). Con respecto a esta equivalencia debo hacer las dos observaciones siguientes. La primera, para advertir que la Directiva no requiere "fijar los precios en un nivel anormal o artificial", sino "difundir información [...] transmitiendo señales falsas [...] o pudiendo así fijar en un nivel anormal o artificial el precio". Sin embargo, la exigencia de beneficio ("cuando [...] obtenga una ventaja o un beneficio"), lleva a concluir que se requerirá la efectiva alteración del precio normal o natural. La segunda, análogamente, pero a la inversa, porque la exigencia de beneficio en las manipulaciones del artículo $284.1 .2^{\circ}$ del Código Penal lleva necesariamente a concluir que la conducta de ofrecimiento de datos económicos total o parcialmente falsos consiguió "alterar o preservar el precio de cotización de un instrumento financiero o un contrato de contado sobre materias primas relacionado o de manipular el cálculo de un índice de referencia".

La manipulación del cálculo de un índice de referencia, prevista en la Directiva en el artículo 5.2.d), puede hacerse corresponder con el delito de alteración de precios (art. 284.1.1 ${ }^{\circ}$, modalidad referida a los "índices de referencia"), pero también con los hechos de ofrecer datos económicos total o parcialmente falsos para "manipular el cálculo de un índice de referencia" (art.

90 Como se ha denunciado, se alude en unas ocasiones a "índices de referencia" (arts. $284.1 .1^{\circ}$ y $3^{\circ}$ ) y, en otra, al "cálculo de un índice de referencia" (art. 284.1.2 ${ }^{\circ}$ y, además, los índices de referencia, no tienen "precio" (véase el art. 284.1.1º). Así, Gómez-Jara Díez/Tejada Plana: op. cit., pp. 7-8. 
$\left.284.1 .2^{\circ}\right)$ y de proporcionar indicios susceptibles de confundir o engañar (artículo $284.1 .3^{\circ}$ C.P. $)^{90}$. De nuevo, deben hacerse, al respecto, las observaciones siguientes: la referencia a la "manipulación del cálculo de un índice de referencia" en la Directiva resulta, en principio, ambigua porque podría interpretarse bien meramente como una maniobra dirigida a manejar el índice de referencia o intervenir en el mismo, bien como su efectiva alteración. La formulación utilizada "transmitir información falsa o engañosa, suministrar datos falsos o engañosos, o cualquier otra conducta que suponga una manipulación del cálculo de un índice de referencia" parece que inclina la interpretación, al decir "que suponga", hacia la idea de que se produzca la modificación o la preservación del índice de referencia. Partiendo de esta conclusión, el delito de alteración de precios (art. 284.1.1. ${ }^{\circ}$ C.P.) se correspondería con la figura de la Directiva al requerir que la manipulación llegue a modificar los índices de referencia. Igualmente, la modalidad de ofrecer datos económicos total o parcialmente falsos para "manipular el cálculo de un índice de referencia" (art. 284.1.2 ), teniendo en cuenta que exige el beneficio y, este, la efectiva manipulación del "cálculo de un índice de referencia". Pero la previsión de la Directiva no se ajusta a la modalidad de proporcionar indicios susceptibles de confundir o engañar (art. $284.1 .3^{\circ}$ C.P.), pues puede integrarse por una conducta que no dé lugar a la efectiva alteración del índice de referencia [como en el caso de las circunstancias b) o, incluso, c)].

Sin embargo, la Directiva carece de una figura paralela a la de aseguramiento de posición dominante. Aquí, el legislador español ha decidido mantener esta modalidad por encima de las exigencias de la Directiva; sin embargo, aunque la conducta estuviera ya prevista en la regulación que resultó de la reforma de 2010 (si bien con otra estructura, al requerir la utilización de información privilegiada), se ignoran las razones para contar aquí con una protección más acusada que la considerada necesaria por la Unión Europea.

La esquemática presentación de las conductas en esta figura no permite obviar, por lo demás, otros aspectos que resultan 
de la comparación. Así, que el Código Penal no ha incorporado como una condición necesaria la obtención de un beneficio en términos análogos a la Directiva. En efecto, el beneficio constituye una condición necesaria en el artículo 5.2, c) de la Directiva que es exigido, tanto con respecto a la modalidad que consiste en fijar precios en un nivel anormal o artificial, correspondiente a la del artículo $284.1 .1^{\circ}$ del Código, que no lo requiere (y, por lo tanto, resulta menos exigente), como con referencia a la forma de transmitir señales falsas o engañosas (que puede verse reflejada en al art. 284.1.2 ${ }^{\circ}$ ). Además, la Directiva alude a "una ventaja o un beneficio" [y su considerando (12), alude a la posibilidad de que sea suficiente el beneficio derivado real o potencial, aunque esta expresión no figura en las disposiciones normativas], con una expresión que claramente es más amplia que la utilizada en el Código Penal "beneficio".

También debe observarse que la Directiva se refiere en la descripción de todas las infracciones penales al precio de "uno o varios instrumentos financieros", y el Código Penal, no. Esto puede acarrear alguna duda, pero si el bien jurídico es la integridad del mercado, no puede determinar la comisión de más de un delito una conducta que afecta a varios instrumentos financieros.

\section{Penalidad}

La penalidad que establece el artículo 284.1 es común a todos los delitos: "pena de prisión de seis meses a seis años, multa de dos a cinco años, o del tanto al triplo del beneficio obtenido o favorecido, o de los perjuicios evitados, si la cantidad resultante fuese más elevada, e inhabilitación especial para intervenir en el mercado financiero como actor, agente o mediador o informador por tiempo de dos a cinco años". La reforma, en este punto, no solamente ha aumentado las penas de prisión (el máximo ha pasado de 2 a 6 años), multa (cuyo anterior máximo es ahora su mínimo) e inhabilitación (por lo que se refiere a la que figuraba en el art. $284.3^{\circ}$, cuyo máximo ha pasado a ser el mínimo de la actual), sino que ha transformado la pena alter- 
nativa antes prevista en una pena conjunta de prisión, multa e inhabilitación ${ }^{91}$.

La dependencia de la pena en el delito de alteración de precios (art. 284.1) del beneficio obtenido o los perjuicios evitados responde al mandato de la Directiva de abuso de mercado ${ }^{92}$. Como ya señalé, a mi modo de ver, no guarda una relación clara con el injusto del delito (a diferencia, por ejemplo, del valor de las drogas en los arts. 368 y ss., relacionado directamente con su cantidad), sino que podría responder, más bien, a razones de política criminal dirigidas a disuadir de cometer el delito ante la amenaza de que la operación manipuladora comporte más daños que ventajas. De todos modos, como ya fue indicado, aunque la multa proporcional (del tanto al triplo) dependa "del beneficio obtenido o favorecido, o de los perjuicios evitados", la consumación del delito podrá tener lugar sin obtenerse el beneficio o sin llegar a evitarse el perjuicio, realizando la inversión o la desinversión correspondiente, bien porque el delito correspondiente no lo requiera, bien porque no se efectuó. De ahí que el legislador haya previsto una modalidad alternativa de pena pecuniaria por el sistema de días-multa (multa de dos a cinco años ${ }^{93}$ ). No obstante, cuando se haya constatado efectivamente el beneficio conseguido o el perjuicio evitado, habrá que optar por la multa que resulte más grave, bien sea la calculada conforme al sistema de días-multa, bien la determinada según el sistema proporcional teniendo como base para el cálculo cualquiera de las que ofrece la ley: el beneficio obtenido o favorecido, o los

91 Sin embargo, tras la reforma, la pena privativa de libertad que corresponde a la tentativa de alteración de precios es sustancialmente menor que antes. Esta diferencia ha sido criticada por Gómez Pavón por no favorecer la mayor protección que busca la Directiva de abuso de mercado (en "El delito de alteración de precios", cit., p. 4).

92 Su considerando (24) señala que "la imposición de sanciones debe ser proporcionada, tomando en consideración los beneficios obtenidos o las pérdidas evitadas".

93 El límite temporal máximo de la pena de días-multa previsto en el artículo 50.3 resulta, así, excedido, como han advertido Gómez-Jara Díez y Tejada Plana (en op. cit., p. 5). 
perjuicios evitados. Aunque la referencia legal que permite esta conclusión ("si la cantidad resultante fuese más elevada") resulte sintácticamente ambigua, considero que su amplitud permite perfectamente entender que deberá escogerse no solo entre la multa calculada según uno u otro sistema, sino también la cantidad que resulte más elevada tomando como referencia, bien el beneficio, bien el perjuicio evitado. Ello cohonesta, además, con la reiterada pretensión político-criminal de la Directiva de abuso de mercado de contar-dentro de los límites de la proporcionalidad-con el mayor efecto disuasorio en los posibles infractores.

No obstante, al mismo tiempo, como se ha señalado, la pena ahora podría resultar excesiva, precisamente, a la vista de la acumulación ${ }^{94}$.

\section{Circunstancias específicas de agravación (art. 284. 2 y 3)}

Los artículos 284.2 y 3 recogen tres circunstancias de agravación aplicables a los delitos de los apartados precedentes (dos estaban ya previstas en parecidos términos en el delito de uso de información relevante del anterior artículo 285). Poseen igual incidencia penológica, de modo que cualquiera que concurra determinará que la pena se aplique en su mitad superior. Pero, puesto que se trata de disposiciones separadas (art. 284, núms. 2 y 3 ), cabe la posibilidad de que el efecto agravatorio sea acumulativo, en la medida en que la pena sobre la que incida la circunstancia agravatoria no sea la del tipo básico, sino la ya agravada. Esto es, que hubiera de apreciarse alguna de las circunstancias del número 2 en un hecho llevado a cabo por un "trabajador o empleado" a los que se refiere el número 3, con lo cual la pena agravada sería la de prisión de 4 años, 7 meses y 15 días a 6 años, multa de 4 años y 3 meses a 5 años (o la proporcional correspondiente) e inhabilitación especial para intervenir

94 Gómez-Jara Díez/Tejada Plana: "La reforma del delito de manipulación de mercado en el Código Penal español”, cit., p. 4.

hitp://dx.doi.org/10.15304/epc.40.6216 -167- 
en el mercado financiero como "actor, agente o mediador o informador" con esta última duración.

Concretamente, las agravaciones son las siguientes:

a) "que el sujeto se dedique de forma habitual a las anteriores prácticas abusivas". Al igual que ocurría en el artículo 285 antes de la reforma, y sucede en otros lugares del Código Penal, la habitualidad no se define. Debe interpretarse que aquí se caracteriza por la reiteración de prácticas abusivas idénticas a las que se contemplan en el artículo $284 \mathrm{y}$, por lo tanto, han de tener carácter delictivo (y no de mera infracción administrativa). Aunque el efecto penológico de esta circunstancia ya no supera tras la reforma al de la agravante genérica de reinciden$\mathrm{cia}^{95}$, la referencia a "las anteriores prácticas abusivas" obliga, en mi opinión, insisto, a considerarlas constitutivas de delito. $\mathrm{Y}$, en consecuencia, a que el sujeto haya sido condenado por los correspondientes hechos. Por razones de estricta legalidad, culpabilidad, presunción de inocencia (y seguridad jurídica), la circunstancia debe interpretarse como una (multi)reincidencia limitada a los delitos del artículo 284, incluido el requisito de que la condena sea firme (o las prácticas abusivas sean probadas en el proceso en que se plantea la aplicación de la figura a la que se refiera la habitualidad ${ }^{96}$ ), de acuerdo con la interpretación secundum constitutionem similar a la que ha sostenido el Tribunal Constitucional en su Sentencia 185/2014 ${ }^{97}$. Tal interpretación

95 Véase, con respecto a la circunstancia del art. 285.2.1 $1^{\mathrm{a}}$, este argumento de Martínez-Buján Pérez para dotar de fuste a la habitualidad (en Derecho penal económico y de la empresa. Parte especial, $5^{\text {a }}$ ed., cit., pp. 369-370).

96 Aunque esto es difícil, a la vista, por una parte, del régimen del delito continuado y, por otra, del hecho de que habría que descartar la aplicación de esta cualificación en el caso de que, de una sola vez, se realizan más de tres abusos de información privilegiada, porque tal hipótesis no habla en el sentido criminológico y técnico-jurídico de la habitualidad, por impreciso que sea, sino en el de la concurrencia.

97 En esta sentencia el TC se ocupó de la interpretación de la "habitualidad" por reiteración de las faltas de hurto (contemplada en el art. 623.1, párrafo segundo, hasta la reforma de 2015). 
excluye, en consecuencia, la posibilidad de que baste la existencia de previas denuncias, imputaciones o condenas no firmes ${ }^{98}$.

No obstante, la fórmula empleada por el legislador incluye elementos valorativos que también requieren concreción y afectan a aspectos tan decisivos como el número de infracciones y al alcance de la proximidad temporal entre las mismas. Con respecto al número de infracciones necesario para apreciarla, la doctrina tratándose de comportamientos habituales exige usualmente al menos $3^{99}$, lo que es también acorde con la práctica jurisprudencial ante otras referencias legales a la habitualidad ${ }^{100}$. Sin embargo, el criterio temporal resulta más impreciso tanto por su dificultad para ser precisado con carácter general. Aunque, desde luego, los hechos deberán tener una cierta proximidad temporal que el término "habitual" comporta semánticamente en la medida en que requiere una continuación.

Por lo demás, tal habitualidad no será compatible con la circunstancia genérica de reincidencia, por razones obvias de bis in idem, siempre que se trate de los mismos delitos.

Pese a que, como se ve, con ciertos apoyos argumentales la indeterminación legal de la fórmula de la habitualidad se puede reducir, esta clase de referencias a comportamientos habituales son excesivamente vagas. Además, su fundamento, basado en la peligrosidad criminal, por un lado, es muy cuestionable

98 Insistiendo en ello, véase la STC 3/2015, F.J. $3^{\circ}$.

99 Faraldo Cabana, P.: “Artículo 285", en Gómez Tomillo, M.: Comentarios prácticos al Código Penal, T. III, Ed. Thomson Reuters Aranzadi, Cizur Menor, 2015, pp. 529-530, con más referencias. Incluso, no se ha descartado la posibilidad de interpretar la habitualidad al modo en que se define en el art. 94 C.P. [así, Morales Prats, F.: “Artículo 285”, en Quintero Olivares, G.(Dir.)/Morales Prats, F. (Coord.): Comentarios al Código Penal español, T. II, $7^{a}$. ed., Ed. Thomson Reuters Aranzadi, Cizur Menor, 2016, pp. $389-$ 390].

100 La L.O. 1/2015 de modificación del Código Penal ha venido a reforzar este criterio pues caracteriza en su preámbulo como un supuesto de "delincuencia habitual" el del nuevo apartado $7^{\circ}$ del art. 235, que requiere que "el culpable hubiera sido condenado ejecutoriamente al menos por tres delitos [...]". 
porque dicha peligrosidad se deduce de la ejecución del hecho, y no de un pronóstico individualizado de peligrosidad ${ }^{101}$. Y, por otro lado, puede dar lugar a tener en cuenta la "habitualidad" ya apreciada en sentencias anteriores, sin el límite que posee la circunstancia de reincidencia para no apreciar antecedentes penales cancelados ${ }^{102}$.

b) que el beneficio obtenido, la pérdida evitada o el perjuicio causado sea de "notoria importancia". Esta circunstancia también agravaba bajo la regulación anterior la responsabilidad por el delito de uso de información relevante. Pese a ello, aunque la doctrina remitía expectante a la valoración que hiciera la jurisprudencia, esta no ayudó por la falta de pronunciamientos sobre el particular. Tras la reforma de 2019, dicho importe deberá ser notoriamente superior a las cantidades que pueden alcanzar el beneficio obtenido o el perjuicio causado que operan como umbrales circunstanciales para la tipicidad de la conducta en tres casos [superior a $250.000 €-\operatorname{art.} 284.1,2^{\circ}$, a) y $3^{\circ}$, a)-; o superior a $500.000 €$ - art. 285.1, a) $]^{103}$.

c) que el responsable del hecho fuera "trabajador o empleado" de una empresa de servicios de inversión ${ }^{104}$, entidad de crédito, autoridad supervisora o reguladora, o entidad rectora de mercados regulados o centros de negociación. Como se puede ver, se trata de sujetos que aparecen profesionalmente

101 Véase, en esta línea, muy crítico, Sanz Morán, A.J.: "La reincidencia y la habitualidad", en Álvarez García, F.J. (Dir.): La adecuación del Derecho penal español al ordenamiento de la Unión Europea. La política criminal europea, Ed. Tirant lo Blanch, Valencia, 2009, p. 64.

102 Precisamente, el fundamento de peligrosidad criminal al que responde supondría un obstáculo para establecer límites con base en la prohibición de bis in idem.

103 Véase, con un argumento análogo, Baucells Lladós, J.: “Artículo 285", en Córdoba Roda, J./García Arán, M. (Dirs.): Comentarios al Código Penal. Parte especial, T. I, Ed. Marcial Pons, Madrid, 2004, p. 1061.

104 La Ley del Mercado de Valores contempla las siguientes clases de empresas de servicios de inversión: las sociedades de valores, las agencias de valores, las sociedades gestoras de carteras y las empresas de asesoramiento financiero (art. 143). 
vinculados con determinados operadores financieros privados $\mathrm{u}$ oficiales o institucionales. Estos sujetos desempeñan funciones rectoras, reguladoras, supervisoras o de servicio, de modo que materialmente cuentan con una capacidad privilegiada de influencia en este ámbito y jurídicamente se les imponen, en consecuencia, determinados deberes. La referencia legal, aunque omite la alusión expresa al personal directivo (a diferencia de lo que se observa en otros delitos, como en los de corrupción en los negocios), permite abarcarlo sin dificultades, considerando la amplitud que adquiere con el término "empleado". De todos modos, la referencia expresa al personal directivo no está de más, por razones expresivas (prevención general) tanto de carácter negativo, como positivo.

\section{Cláusulas de extensión del alcance típico}

La nueva regulación de los delitos de manipulación de mercado y uso de información privilegiada ha extendido el alcance de las figuras típicas de los artículos 284 y 285 mediante la inclusión de los artículos 285 ter y 285 quáter. En el primero se halla una amplia y vaga cláusula de remisión que extiende las previsiones del artículo 284 a los instrumentos financieros y contratos "previstos en la normativa europea y española en materia de mercado e instrumentos financieros" (art. 285 ter). De este modo, las enumeraciones de los distintos objetos de los delitos pasan a poseer un carácter abierto a nuevas incorporaciones que en el futuro puedan llevar a cabo el Derecho europeo o el español. La disposición dota a los artículos de referencia del carácter de leyes penales en blanco en este punto. Y aquí la remisión cumple, ciertamente, una de las funciones esenciales de esta técnica legislativa, como es la necesidad de previsión de nuevas necesidades de intervención punitiva ${ }^{105}$; aquí, como

105 Sobre estas cláusulas, Doval Pais, A.: Posibilidades y límites para la formulación de las normas penales. El caso de las leyes en blanco, Ed. Tirant lo Blanch, Valencia, 1999, pp. 107-114. 
entiende la doctrina especializada, completamente obvia ${ }^{106}$. El inconveniente del uso de estos recursos normativos es, como se sabe, la indeterminación que acarrea al texto legal, aunque ciertamente este ya se encuentra abierto por las amplias referencias a los objetos que se han visto.

El artículo 285 quáter, por su parte, y también como novedad, extiende el castigo de los actos preparatorios de los artículos 17 y 18 del Código a estos delitos, quizá pretendiendo satisfacer cumplidamente [es decir, más allá del castigo de la inducción, art. 28, a)] el vago mandato de la Directiva de abuso de mercado de que los Estados miembros garanticen que la "incitación a cometer las infracciones penales" sea punible como infracción penal (art. 6.1). De modo que el rango de las conductas que quedan abarcadas por la nueva regulación de los delitos es muy amplio.

\section{Conclusiones}

La Directiva de abuso de mercado ofrecía una ocasión para revisar la política criminal en esta materia a la vista de las obligaciones mínimas que establecía y después de la experiencia de los años transcurridos desde la reforma de 2010. Sin embargo, el legislador español ha optado por cumplir tarde y mal con el mandato impuesto.

La reforma de los delitos de manipulación de mercado efectuada por la L.O. 1/2019 ha supuesto una mejor regulación, hasta cierto punto, de los correspondientes delitos, pero no puede afirmarse que haya transpuesto correctamente el contenido de

106 La necesidad de actualización se pone también claramente de manifiesto en la Ley del Mercado de Valores, al habilitarse expresamente al Gobierno para modificar mediante real decreto la relación de instrumentos financieros que proporciona en su Anexo con la finalidad de adaptarlo a las modificaciones que se establezcan en la normativa de la Unión Europea (art. 2.1 del R.D.L. 4/2015 por el que se aprueba el texto refundido de la Ley del Mercado de Valores). 
la Directiva de abuso de mercado. Se trataba de una tarea difícil que ha sido resuelta de un modo precipitado, simplista y, como consecuencia, defectuoso.

El alcance de las nuevas figuras es más amplio, como requería en varios aspectos la intervención penal en este ámbito, pero hay motivos para el pesimismo. Por una parte, el desajuste con la Directiva. La razón de este juicio no se halla principalmente en la sobrepenalización que el legislador español no ha evitado, con respecto al contenido punitivo mínimo establecido por la Directiva, sino en la difícil congruencia que puede hallarse entre las infracciones penales que diseña la norma europea y las figuras típicas resultantes de la modificación legal. De todas formas, aunque se ha sugerido que, después de todo, hubiera sido mejor transcribir la Directiva ${ }^{107}$, ello tampoco hubiera sido tan fácil, porque las conductas punibles tampoco están tan claras en su formulación ni en su regulación (entre otras razones, al encontrarse aspectos fundamentales de las mismas en la parte no dispositiva de la norma ${ }^{108}$ ).

Además, el producto resultado de la reforma es verdaderamente confuso y, a pesar de los serios esfuerzos interpretativos que ya se han empezado a llevar a cabo y de otros que cabe esperar, puede augurarse a las nuevas figuras una vida práctica accidentada y, seguramente, tan escasa como lo ha sido hasta ahora.

Incluso, la vaga amplitud de la tipicidad puede colidir con prácticas habituales en los mercados que, comportando desajustes o movimientos inesperados, de algún modo cuentan con que ocurren y pueden poseer, además, algunas ventajas (como la mayor liquidez o la innovación financiera ${ }^{109}$ ). Es el problema de los "casos límite" ${ }^{110}$. ¿Pertenecen al ámbito típico compor-

107 Gómez-Jara Díez: El delito de manipulación de mercado, cit., p. 13.

108 En efecto, en los considerandos se avanza un auténtico contenido dispositivo que las propias normas no recogen, después, en los mismos términos.

109 Dodd: "Transacciones", cit., p. 20.

110 Dodd: op. cit., pp. 16-18. 
tamientos que pertenecen a la lógica de las interacciones en el mundo de los mercados? ?11 $^{11}$

Y también cabe cuestionar, incluso, la propia intervención de la Unión Europea con el instrumento penal por razones de subsidiariedad, al presuponer que la gran crisis que estalló en 2008 ha sido la prueba de la necesidad del Derecho penal en esta materia; una conclusión sumamente parcial, que ignora otras razones de la frustración de las expectativas normativas (como la constatada falta de aplicación de sanciones administrativas en el caso de España) ${ }^{112}$.

En torno a esta materia, no obstante, late la cuestión de fondo de si, aun siendo lo más correcto que las finanzas y la economía real se hallen vinculadas, es aún posible proteger la integridad de un mercado que no solo funciona como un mecanismo para la eficiencia productiva del sistema económico, sino también para intereses de enriquecimiento utilizando estrategias de juego similares a las de un casino.

\section{BIBLIOGRAFÍA}

BAJO FERNÁNDEZ, M.: Manual de Derecho penal (Parte Especial). Delitos patrimoniales y económicos, Ed. Ceura, Madrid, 1987.

BOIX REIG, J.: "Las prácticas restrictivas de la competencia en el Proyecto de Código Penal de 1980", en Cuadernos de Política Criminal, núm. 16, 1982, pp. 35-47.

111 Sobre esta idea gira la obra dirigida por J.-Ma Silva Sánchez titulada ¿Libertad económica o fraudes punibles? Riesgos penalmente relevantes e irrelevantes en la actividad económico-empresarial, Ed. Marcial Pons, Madrid, 2003, en cuya Introducción (p. 11) plantea la pregunta que reproduzco, de un modo afín, en el texto.

112 Estrada i Cuadras: "Presente y futuro del delito de alteración de precios (art. 284 Cp)", cit., pp. 27 y 42 (con elocuentes datos sobre las actuaciones de la CNMV durante los años 2007-2012). 
BRAGE CENDÁN, S.B.: Los delitos de alteración de precios. Especial referencia a los artículos 262, 281 y 284 CP, Ed. Comares, Granada, 2001.

CANCIO MELIÁ, M.: "Caso BANKIA/Preferentes: Fraude masivo y Derecho Penal", en Corcoy Bidasolo, M./Gómez Martín, V. (Dirs.): Fraude a consumidores y Derecho penal. Fundamentos y talleres de leading cases, Ed. B. de f, Montevideo-Buenos Aires, 2016, pp. 409-436.

DE LA MATA BARRANCO, N.: Derecho penal europeo y legislación española: Las reformas del Código Penal, Ed. Tirant lo Blanch, Valencia, 2015.

DODD, R.: "Transacciones", en Finanzas \& Desarrollo, marzo 2010, pp. 26-28.

DOVAL PAIS, A.: Posibilidades y límites para la formulación de las normas penales. El caso de las leyes en blanco, Ed. Tirant lo Blanch, Valencia, 1999.

ESTRADA I CUADRAS, A.: "Presente y futuro del delito de alteración de precios (art. 284 Cp)", en InDret, 1/2014.

FARALDO CABANA, P.: "Algunos aspectos del delito de uso de información reservada en el mercado de valores en el proyecto de Código Penal de 1994", en Estudios penales y criminológicos, núm. 18, 1994-1995, pp. 45-122.

FARALDO CABANA, P.: “Artículo 285”, en Gómez Tomillo, M. (Dir.): Comentarios prácticos al Código Penal, T. III, Ed. Thomson Reuters Aranzadi, Cizur Menor, 2015.

FEIJOO SÁNCHEZ, B.: Orden socioeconómico y delito. Cuestiones actuales de los delitos económicos, Ed. B de f, Montevideo-Buenos Aires, 2016.

FEIJOO SÁNCHEZ, B.: "Los delitos de manipulación del precio de cotización de un instrumento financiero del art. 284 CP tras la LO 1/2019. Retos dogmáticos frente a un desatino legislativo", en La Ley Penal. Revista de Derecho penal, procesal y penitenciario, núm. 138, 2019.

FERNÁNDEZ ALBOR, A.: El agio arrendaticio, Ed. Tecnos, Madrid, 1969. 
FERNÁNDEZ PÉREZ, N.: "La contratación en los mercados secundarios oficiales", en Campuzano, A.B./ Conlledo Lantero, F./Palomo Zurdo, R.J. (Dirs.): Los mercados financieros, 2a . ed., Ed. Tirant lo Blanch, Valencia, 2017, pp. 765-796.

GALÁN MUÑOZ, A.: "Mentiras y medias verdades en los mercados financieros. Una aproximación crítica a la posible incriminación de las «erróneas» calificaciones realizadas por las agencias de calificación crediticia", en Tamarit Sumalla, J.M ${ }^{\mathrm{a}}$./Morales Prats, F./García Albero, R.: Represión Penal y Estado de Derecho. Homenaje al Profesor Gonzalo Quintero Olivares, Ed. Aranzadi, Cizur Menor, 2018, pp. 639-679.

GARCÍA-PABLOS DE MOLINA, A: "Sobre la figura del delito para alterar los precios (naturales) de las cosas", en Cuadernos de Política Criminal, núm. 14, 1981. pp. 221-244. GÓMEZ-JARA DÍEZ, C.: El delito de manipulación de mercado (arts. 284.2 y $284.3 \mathrm{CP}$ ), Ed. Tirant lo Blanch, Valencia, 2017.

GÓMEZ-JARA DÍEZ, C./Tejada Plana, D.: "La reforma del delito de manipulación de mercado en el Código Penal español: luces, sombras y algún claroscuro", en La Ley, núm. 3974, 2019.

GÓMEZ PAVÓN, P.: “Algunas cuestiones en torno al art. 284 del Código Penal", en López Barja de Quiroga, J./Zugaldía Espinar, J.M. (Coords.): Dogmática y Ley penal. Libro homenaje a Enrique Bacigalupo, T. II, Ed. Marcial Pons, Madrid, 2004, pp. 951-967.

GÓMEZ PAVÓN, P.: "El delito de alteración de precios", en $L a$ Ley Penal: Revista de Derecho penal, procesal y penitenciario, núm. 137, 2019.

LUCHTMAN, M.J.J.P./VERVAELE, J.A.E.: “Aplicación del régimen de abuso de mercado (operaciones con información privilegiada y la manipulación del mercado): ¿Hacia un modelo integrador de la aplicación de la ley penal y administrativa en la UE?", en Pérez Cepeda, A.I. (Dir.): 
Política criminal ante el reto de la delincuencia transnacional, Ed. Universidad de Salamanca-Tirant lo Blanch, Salamanca, Valencia, 2016, pp. 751-794.

MARTÍNEZ-BUJÁN PÉREZ, C.: Derecho penal económico y de la empresa. Parte especial, $5^{\mathrm{a}}$ ed. Ed. Tirant lo Blanch, Valencia, 2015.

MORALES PRATS, F.: “Artículo 285”, en Quintero Olivares, G.(Dir.)/Morales Prats, F. (Coord.): Comentarios al Código Penal español, T. II, 7 ${ }^{\mathrm{a}}$. ed., Ed. Thomson Reuters Aranzadi, Cizur Menor, 2016.

NIETO MARTÍN, A.: "El insider trading despierta de su largo sueño. A propósito de la Sentencia del Tribunal Supremo de 23 de julio de 2015", en el blog de Jesús Alfaro, Universidad Autónoma de Madrid, "Almacén de Derecho", 4 de enero 2016 (https://almacendederecho.org/insidertrading-o-trafico-con-informacion-privilegiada/).

ORTIZ DE URBINA GIMENO, I.: "Selección de bienes jurídico-penales conforme a la Constitución: El caso de la protección de la competencia", en Silva Sánchez, J.-Ma ./ Queralt Jiménez, J./Corcoy Bidasolo, M./Castiñeira Palou, Mª.T. (Edits.): Estudios de Derecho penal. Homenaje al profesor Santiago Mir Puig, Ed. B de F, Buenos Aires (Argentina), 2017, pp. 1121- 1130.

PALMA HERRERA, J.M.: "Sobre la posible responsabilidad penal de Bankia, BFA y algunos de sus administradores por el tema de las preferentes", en Miranda Serrano, Luis María (Dir.): La protección de los consumidores en tiempos de cambio. Ponencias y Comunicaciones del XIII Congreso de la Asociación Sainz de Andino, Ed. Iustel, Madrid, 2015.

PAREDES CASTAÑÓN, J.M.: "Problemas de tipicidad en las conductas de manipulación de precios de los mercados de valores", en Demetrio Crespo, E. (Dir.): Crisis financiera y Derecho penal económico, Ed. Edisofer, Buenos Aires, 2014, pp. 215-276. https://doi.org/10.17230/nfp.10.82.2 
PÉREZ GUERRA, M.: "El abuso de mercado: «business as usual» en las operaciones de derivados", en La Ley, núm. 4677, 2015.

QUINTERO OLIVARES, G.: "Maquinaciones para alterar el precio de las cosas", en Nueva Enciclopedia Jurídica, T. XV, Ed. Seix, 1974, pp. 842-849.

QUINTERO OLIVARES, G.: “Art. 284”, en Quintero Olivares, G. (Dir.)/Morales Prats, F. (Coord..): Comentarios a la Parte Especial del Derecho penal, $3^{\mathrm{a}}$ ed., Ed. Aranzadi, Cizur Menor, 2002.

SANZ MORÁN, A.J.: "La reincidencia y la habitualidad", en Álvarez García, F.J. (Dir.): La adecuación del Derecho penal español al ordenamiento de la Unión Europea. La política criminal europea, Ed. Tirant lo Blanch, Valencia, 2009.

SILVA SÁNCHEZ, J.-Ma.$:$ (Dir.): ¿Libertad económica o fraudes punibles? Riesgos penalmente relevantes e irrelevantes en la actividad económico-empresarial, Ed. Marcial Pons, Madrid, 2003. 